NBER WORKING PAPER SERIES

\title{
THE TIME VARYING VOLATILITY OF MACROECONOMIC FLUCTUATIONS
}

\author{
Alejandro Justiniano \\ Giorgio E. Primiceri \\ Working Paper 12022 \\ http://www.nber.org/papers/w12022
}

\author{
NATIONAL BUREAU OF ECONOMIC RESEARCH \\ 1050 Massachusetts Avenue \\ Cambridge, MA 02138 \\ February 2006
}

The views expressed herein are those of the author(s) and do not necessarily reflect the views of the National Bureau of Economic Research.

C2006 by Alejandro Justiniano and Giorgio E. Primiceri. All rights reserved. Short sections of text, not to exceed two paragraphs, may be quoted without explicit permission provided that full credit, including () notice, is given to the source. 
The Time Varying Volatility of Macroeconomic Fluctuations

Alejandro Justiniano and Giorgio E. Primiceri

NBER Working Paper No. 12022

February 2006

JEL No. E30, C32

\begin{abstract}
$\underline{\text { ABSTRACT }}$
In this paper we investigate the sources of the important shifts in the volatility of U.S. macroeconomic variables in the postwar period. To this end, we propose the estimation of DSGE models allowing for time variation in the volatility of the structural innovations. We apply our estimation strategy to a large-scale model of the business cycle and find that investment specific technology shocks account for most of the sharp decline in volatility of the last two decades.

Alejandro Justiniano

Division of Monetary Affairs

Board of Governors of the Federal Reserve System

Washington, DC 20551

alejandro.justiniano@frb.gov

Giorgio E. Primiceri

Department of Economics

Northwestern University

2001 Sheridan Road

Evanston, IL 60208

and NBER

g-primiceri@northwestern.edu
\end{abstract}




\title{
THE TIME VARYING VOLATILITY OF MACROECONOMIC FLUCTUATIONS
}

\author{
ALEJANDRO JUSTINIANO AND GIORGIO E. PRIMICERI
}

\begin{abstract}
In this paper we investigate the sources of the important shifts in the volatility of U.S. macroeconomic variables in the postwar period. To this end, we propose the estimation of DSGE models allowing for time variation in the volatility of the structural innovations. We apply our estimation strategy to a large-scale model of the business cycle and find that investment specific technology shocks account for most of the sharp decline in volatility of the last two decades.
\end{abstract}

\section{IntRoduCtion}

It has been well documented that the volatility of output, inflation, interest rates and many other macroeconomic variables of the U.S. economy has exhibited a very high degree of time variation over the last fifty years (see, for instance, Sims and Zha (2004) or Stock and Watson (2003a)). Perhaps, the most notorious episode of substantial volatility shift in recent U.S. economic history is the "Great Moderation," ${ }^{1}$ which corresponds to the sharp decline in the standard deviation of output as well as other macroeconomic and financial variables since the mid 1980s. While significant efforts have been devoted to determine the timing of the Great Moderation (see, among others, Kim and Nelson (1999), McConnell and PerezQuiros (2000), Stock and Watson (2002), Chauvet and Potter (2001), Herrera and Pesavento (2005)), there have been surprisingly few studies attempting to identify the structural disturbances responsible for these volatility changes.

Date: First draft: July 2005. This version: January 2006.

We would like to thank Jinill Kim, Ernst Schaumburg, Jim Stock and seminar participants at the Sveridge Riksbank, Northwestern University, Ohio State University and the 2005 International Conference on Computing in Economics and Finance for comments. We are also grateful to Riccardo Di Cecio for providing some of the investment deflators data. The views in this paper are solely the responsibility of the authors and should not be interpreted as reflecting the views of the Board of Governors of the Federal Reserve System or any other person associated with the Federal Reserve System.

${ }^{1}$ The name Great Moderation is due to Stock and Watson (2002), although the phenomenon was first noted by Kim and Nelson (1999) and McConnell and Perez-Quiros (2000). 
In this paper we fill this gap, by estimating a DSGE model in which the volatility of the structural innovations is allowed to change over time. First, we describe an algorithm that allows for simultaneous inference on both the model's parameters and the stochastic volatilities. Then, we apply our modeling and estimation strategy to a large-scale business cycle model of the U.S. economy, along the lines of Christiano, Eichenbaum, and Evans (2005) and Smets and Wouters (2003). The model exhibits a number of real and nominal frictions, and various shocks with a precise microeconomic interpretation. The novelty of our set-up is that all of these shocks have variances that can fluctuate over time.

We believe that this is an interesting innovation because it enables us to identify the sources of the changes in the volatility of the main macro variables during the postwar period. Thereafter, we are able to shed light on the nature of the underlying disturbances responsible for the Great Moderation and other shifts in the volatility of the U.S. business cycle.

The main conclusions we reach in this study are as follows. First, the exogenous structural disturbances hitting the U.S. economy display substantial stochastic volatility. Nonetheless, the degree of time variation in variances differs considerably across shocks, being more pronounced for technology disturbances and, particularly, monetary policy shocks. Consequently, while stochastic volatility is present in all of the model's observed endogenous variables, different series exhibit contrasting patterns of fluctuations in their variances.

Second, the decline in the volatility of output, investment, hours and consumption in the early 1980s is largely driven by investment specific technology shocks. These shocks have an equivalent interpretation of disturbances to the inverse of the price of investment in terms of consumption goods. We corroborate our finding that investment specific technology shocks have become less volatile by documenting a decline in the standard deviation of the relative price of investment. Moreover, motivated by Chari, Kehoe, and McGrattan (2005), we suggest an interpretation of these disturbances as proxying for investment financial frictions. In line with this interpretation, we rely on evidence outside our DSGE model to show that financial frictions did indeed decline at the beginning of the 1980s, particularly in mortgage financing.

From the methodological standpoint, this paper is related to the statistics literature on stochastic volatility models (for an overview, see Kim, Shephard, and Chib 
(1998)) and, more generally, on partial non-Gaussian state-space models (Shephard (1994)). Drawing from this literature, we develop an efficient algorithm, based on Bayesian Markov chain Monte Carlo (MCMC) methods, for the numerical evaluation of the posterior of the parameters of interest. Methodologically, the paper closest to ours is Laforte (2005), although in his analysis the time varying variances are modeled as Markov switching as opposed to the smoother processes in the analysis here.

Regarding the application of these techniques, this paper is related to the large literature using estimated micro-founded models to understand the main sources of U.S. business cycle fluctuations (see, for instance, Rotemberg and Woodford (1997), Ireland (2004), Christiano, Eichenbaum, and Evans (2005), Smets and Wouters (2003), Altig, Christiano, Eichenbaum, and Linde (2005)). However, as mentioned, we depart from previous work in this area by allowing for time variation in the volatility of the structural disturbances. Our approach is also linked to the fairly large literature dealing with the estimation of vector autoregressions with heteroskedastic shocks (see, for example, Bernanke and Mihov (1998), Cogley and Sargent (2003), Sims and Zha (2004), Primiceri (2005) or Canova, Gambetti, and Pappa (2005)). In contrast to this strand of work, one advantage of our analysis is that a fully-fledged model provides an easy interpretation for the structural disturbances hitting the economy.

The paper is organized as follows. Section 2 presents the class of models we will deal with and outlines some methodological issues, with the details relegated to an appendix. Section 3 and 4 illustrate our application to the model of the U.S. business cycle and sketch the estimation technique. Section 5 and 6 discuss the estimation results and address the causes of the Great Moderation. Section 7 concludes with some final remarks and priorities for future research.

\section{Stochastic Volatility in DSGE Models}

The general class of models we will work with is summarized by the following system of equations:

$$
E_{t}\left[f\left(y_{t+1}, y_{t}, y_{t-1}, \eta_{t}, \theta\right)\right]=0
$$

where $y_{t}$ is a $k \times 1$ vector of states and endogenous variables, $\eta_{t}$ is an $n \times 1$ vector of exogenous disturbances, $\theta$ is a $p \times 1$ vector of structural parameters and $E_{t}$ denotes the mathematical expectation operator, conditional on the information available at 
time $t$. For example, (2.1) can be thought as a collection of constraints and first order conditions derived from a micro-founded model of consumers and/or firms behavior. The novelty here is that the standard deviation of the elements of $\eta_{t}$ is allowed to change over time. In particular, we make the assumption that

$$
\begin{aligned}
\log \eta_{t} & \equiv \hat{\eta}_{t}=\Sigma_{t} \varepsilon_{t} \\
\varepsilon_{t} & \sim N\left(0, I_{n}\right),
\end{aligned}
$$

where $N$ indicates the normal distribution, $I_{n}$ denotes an $n \times n$ identity matrix and $\Sigma_{t}$ is a diagonal matrix with the $n \times 1$ vector $\sigma_{t}$ of time varying standard deviations on the main diagonal. Following the stochastic volatility literature (see, for instance, Kim, Shephard, and Chib (1998)), we assume that each element of $\sigma_{t}$ evolves (independently) according to the following stochastic processes:

$$
\begin{aligned}
\log \sigma_{i, t} & =\left(1-\rho_{\sigma_{i}}\right) \log \sigma_{i}+\rho_{\sigma_{i}} \log \sigma_{i, t-1}+\nu_{i, t} \\
\nu_{i, t} & \sim N\left(0, s_{i}^{2}\right) \quad i=1, \ldots, n .
\end{aligned}
$$

Observe that modeling the logarithm of $\sigma_{t}$, as opposed to $\sigma_{t}$ itself, ensures that the standard deviation of the shocks remains positive at every point in time.

Our objective is to characterize the posterior distribution of the model structural parameters $(\theta)$ and the time varying volatility of the shocks $\left(\left\{\sigma_{t}\right\}_{t=1}^{T}\right)$. Note that the model described by (2.1) is in general nonlinear and its solution does not have a closed-form expression. Therefore, an approximation of the solution is required. Observe also that commonly used log-linearization methods would not serve our purposes, as the time varying standard deviations would disappear under this approximation. Moreover, log-linear methods would be accurate in this set-up only if the variability of the standard deviations were small. Higher order approximations would instead preserve the interaction term $\Sigma_{t} \varepsilon_{t}$. However, the additional nonlinear terms generated in this case would considerably complicate the estimation. ${ }^{2}$ For these reasons, we develop what we call a partially nonlinear approximation of the model, which combines the appeal for our purposes of both log-linearization and higher order approximations. In particular, we approximate the solution of the model by the partially nonlinear function

$$
\hat{y}_{t}=A \hat{y}_{t-1}+B \hat{\eta}_{t}=A \hat{y}_{t-1}+B \Sigma_{t} \varepsilon_{t},
$$

\footnotetext{
2 There has been recent work estimating nonlinear DSGE models, as in Fernandez-Villaverde and Rubio-Ramirez (2004) or An and Schorfheide (2005). However, these methods have been applied only to small scale models.
} 
where $\hat{y}_{t}$ denotes $\log$ deviations from the non-stochastic steady state of the variable $y$. Appendix A proves that (2.3) represents a valid approximation of the model solution.

\section{The Model}

We apply our method to a relatively large-scale model of the U.S. business cycle, which has been shown to fit the data fairly well (Del Negro, Schorfheide, Smets, and Wouters (2004)). The model is based on work by Christiano, Eichenbaum, and Evans (2005) and Smets and Wouters (2003), to which the reader is referred for additional details. Our brief illustration of the model follows closely Del Negro, Schorfheide, Smets, and Wouters (2004).

3.1. Final goods producers. At every point in time $t$, perfectly competitive firms produce the final consumption good $Y_{t}$, using the intermediate goods $Y_{t}(i), i \in[0,1]$ and the production technology

$$
Y_{t}=\left[\int_{0}^{1} Y_{t}(i)^{\frac{1}{1+\lambda_{p, t}}} d i\right]^{1+\lambda_{p, t}}
$$

$\lambda_{p, t}$ follows the exogenous stochastic process

$$
\log \lambda_{p, t}=\left(1-\rho_{p}\right) \log \lambda_{p}+\rho_{p} \log \lambda_{p, t-1}+\sigma_{p, t} \varepsilon_{p, t},
$$

where $\varepsilon_{p, t}$ is i.i.d.N $(0,1)$ and $\sigma_{p, t}$ evolves as in (2.2). Unless otherwise noticed, this property of a time varying variance applies to all shocks in the model. Profit maximization and zero profit condition for the final goods producers imply the following relation between the price of the final good $\left(P_{t}\right)$ and the prices of the intermediate goods $\left(P_{t}(i), i \in[0,1]\right)$

$$
P_{t}=\left[\int_{0}^{1} P_{t}(i)^{\frac{1}{\lambda_{p, t}}} d i\right]^{\lambda_{p, t}}
$$

and the following demand function for the intermediate good $i$ :

$$
Y_{t}(i)=\left(\frac{P_{t}(i)}{P_{t}}\right)^{-\frac{1+\lambda_{p, t}}{\lambda_{p, t}}} Y_{t} .
$$

As a consequence, $\lambda_{p, t}$ will also correspond to the price mark-up over marginal costs for the firms producing intermediate goods. 
3.2. Intermediate goods producers. A monopolistic firm produces the intermediate good $i$ using the following production function:

$$
Y_{t}(i)=\max \left\{A_{t}^{1-\alpha} K_{t}(i)^{\alpha} L_{t}(i)^{1-\alpha}-A_{t} F ; 0\right\},
$$

where, as usual, $K_{t}(i)$ and $L_{t}(i)$ denote respectively the capital and labor input for the production of good $i, F$ represents a fixed cost of production and $A_{t}$ is an exogenous stochastic process capturing the effects of technology. In particular, we model $A_{t}$ as a unit root process, with a growth rate $\left(z_{t} \equiv \log \frac{A_{t}}{A_{t-1}}\right)$ that follows the exogenous process

$$
z_{t}=\left(1-\rho_{z}\right) \gamma+\rho_{p} z_{t-1}+\sigma_{z, t} \varepsilon_{z, t}
$$

As in Calvo (1983), a fraction $\xi_{p}$ of firms cannot re-optimize their prices and, as we allow for indexation, set their prices following the rule

$$
P_{t}(i)=P_{t-1}(i) \pi_{t-1}^{\iota_{p}} \pi^{1-\iota_{p}}
$$

where $\pi_{t}$ is defined as $\frac{P_{t}}{P_{t-1}}$ and $\pi$ denotes the steady state value of $\pi_{t}$. Subject to the usual cost minimization condition, re-optimizing firms choose their price $\left(\tilde{P}_{t}(i)\right)$ by maximizing the present value of future profits

$$
E_{t} \sum_{s=0}^{\infty} \xi_{p}^{s} \beta^{s} \lambda_{t+s}\left\{\left[\tilde{P}_{t}(i)\left(\Pi_{j=0}^{s} \pi_{t-1+j}^{\iota_{p}} \pi^{1-\iota_{p}}\right)\right] Y_{t+s}(i)-\left[W_{t} L_{t}(i)+R_{t}^{k} K_{t}(i)\right]\right\},
$$

where $\lambda_{t+s}$ is the marginal utility of consumption, $W_{t}$ and $R_{t}^{k}$ denote respectively the wage and the rental cost of capital.

3.3. Households. Firms are owned by a continuum of households, indexed by $j \in[0,1]$. As in Erceg, Henderson, and Levin (2000), while each household is a monopolistic supplier of specialized labor $\left(L_{t}(j)\right)$, a number of 'employment agencies' combines households' specialized labor into labor services available to the intermediate firms

$$
L_{t}=\left[\int_{0}^{1} L_{t}(j)^{\frac{1}{1+\lambda w}} d j\right]^{1+\lambda_{w}} .
$$

Profit maximization and a zero profit condition for the perfectly competitive employment agencies imply the following relation between the wage paid by the intermediate firms and the wage received by the supplier of specialized labor $L_{t}(j)$

$$
W_{t}=\left[\int_{0}^{1} W_{t}(j)^{\frac{1}{\lambda_{w}}} d j\right]^{\lambda_{w}}
$$


and the following labor demand function for labor type $j$ :

$$
L_{t}(j)=\left(\frac{W_{t}(j)}{W_{t}}\right)^{-\frac{1+\lambda w}{\lambda w}} L_{t} .
$$

Each household maximizes the utility function ${ }^{3}$

$$
E_{t} \sum_{s=0}^{\infty} \beta^{s} b_{t+s}\left[\log \left(C_{t+s}(j)-h C_{t+s-1}(j)\right)-\varphi_{t+s} \frac{L_{t+s}(j)^{1+\nu}}{1+\nu}\right]
$$

where $C_{t}(j)$ is consumption, $h$ is the "degree" of internal habit formation, $\varphi_{t}$ is a preference shock that affects the marginal disutility of labor and $b_{t}$ is a "discount factor" shock affecting both the marginal utility of consumption and the marginal disutility of labor. These two shocks follow the stochastic processes

$$
\begin{aligned}
\log b_{t} & =\rho_{b} \log b_{t-1}+\sigma_{b, t} \varepsilon_{b, t} \\
\log \varphi_{t} & =\left(1-\rho_{\varphi}\right) \log \varphi+\rho_{\varphi} \log \varphi_{t-1}+\sigma_{\varphi, t} \varepsilon_{\varphi, t} .
\end{aligned}
$$

The household budget constraint is given by

$$
\begin{gathered}
P_{t+s} C_{t+s}(j)+P_{t+s} I_{t+s}(j)+B_{t+s}(j) \leq R_{t+s-1} B_{t+s-1}(j)+Q_{t+s-1}(j)+\Pi_{t+s}+ \\
+W_{t+s}(j) L_{t+s}(j)+R_{t+s}^{k}(j) u_{t+s}(j) \bar{K}_{t+s-1}(j)-P_{t+s} a\left(u_{t+s}(j)\right) \bar{K}_{t+s-1}(j),
\end{gathered}
$$

where $I_{t}(j)$ is investment, $B_{t}(j)$ denotes holding of government bonds, $R_{t}$ is the gross nominal interest rate, $Q_{t}(j)$ is the net cash flow from participating in state contingent securities, $\Pi_{t}$ is the per-capita profit that households get from owning the firms. Households own capital and choose the capital utilization rate which transforms physical capital $\left(\bar{K}_{t}(j)\right)$ into effective capital

$$
K_{t}(j)=u_{t}(j) \bar{K}_{t-1}(j),
$$

which is rented to firms at the rate $R_{t}^{k}(j)$. The cost of capital utilization is $a\left(u_{t+s}(j)\right)$ per unit of physical capital. Following Altig, Christiano, Eichenbaum, and Linde (2005), we assume that $u_{t}=1$ and $a\left(u_{t}\right)=0$ in steady state. In our partially nonlinear approximation of the model solution, only the curvature of the function $a$ in steady state needs to be specified, $\chi \equiv \frac{a^{\prime \prime}(1)}{a^{\prime}(1)}$. The usual physical capital accumulation equation is described by

$$
\bar{K}_{t}(j)=(1-\delta) \bar{K}_{t-1}(j)+\mu_{t}\left(1-S\left(\frac{I_{t}(j)}{I_{t-1}(j)}\right)\right) I_{t}(j),
$$

where $\delta$ denotes the depreciation rate and, as in Christiano, Eichenbaum, and Evans (2005) and Altig, Christiano, Eichenbaum, and Linde (2005), the function

\footnotetext{
${ }^{3}$ We assume a cashless limit economy as described in Woodford (2003).
} 
$S$ captures the presence of adjustment costs in investment, with $S^{\prime}=0$ and $S^{\prime \prime}>$ 0. Lucca (2005) shows that this formulation of the adjustment cost function is equivalent (up to a first order approximation of the model) to a generalization of a time to build assumption. As in Greenwood, Hercowitz, and Krusell (1997) and Fisher $(2005), \mu_{t}$ is a random shock to the production technology of capital goods and evolves following the exogenous process

$$
\log \mu_{t}=\rho_{\mu} \log \mu_{t-1}+\sigma_{\mu, t} \varepsilon_{\mu, t}
$$

Following Erceg, Henderson, and Levin (2000), in every period a fraction $\xi_{w}$ of households cannot re-optimize their wages and, therefore, set their wages following the indexation rule

$$
W_{t}(j)=W_{t-1}(j)\left(\pi_{t-1} e^{z_{t-1}}\right)^{\iota_{w}}\left(\pi e^{\gamma}\right)^{1-\iota_{w}}
$$

The remaining fraction of re-optimizing households set their wages by maximizing

$$
E_{t} \sum_{s=0}^{\infty} \xi_{w}^{s} \beta^{s} b_{t+s}\left\{-\varphi_{t+s} \frac{L_{t+s}(j)^{1+\nu}}{1+\nu}\right\}
$$

subject to the labor demand function.

3.4. Monetary and Government Policies. Monetary policy sets short term nominal interest rates following a Taylor type rule. In particular, the rule allows for interest rate smoothing and interest rate responses to deviations of inflation from the steady state and deviations of output from trend level:

$$
\frac{R_{t}}{R}=\left(\frac{R_{t-1}}{R}\right)^{\rho_{R}}\left[\left(\frac{\pi_{t}}{\pi}\right)^{\phi_{\pi}}\left(\frac{Y_{t} / A_{t}}{Y / A}\right)^{\phi_{Y}}\right]^{1-\rho_{R}} e^{\sigma_{R, t} \varepsilon_{R, t}},
$$

where $R$ is the steady state for the gross nominal interest rate and $\varepsilon_{R, t}$ is a monetary policy shock. We also consider an alternative specification of the policy rule, in which the monetary authority responds to output growth.

Fiscal policy is assumed to be fully Ricardian and public spending is given by

$$
G_{t}=\left(1-\frac{1}{g_{t}}\right) Y_{t}
$$

where $g_{t}$ is an exogenous disturbance following the stochastic process

$$
\log g_{t}=\left(1-\rho_{g}\right) \log g+\rho_{g} \log g_{t-1}+\sigma_{g, t} \varepsilon_{g, t}
$$

3.5. Market Clearing. The resource constraint is given by

$$
C_{t}+I_{t}+G_{t}+a\left(u_{t}\right) \bar{K}_{t-1}=Y_{t}
$$


3.6. Steady State and Model Solution. Since the technology process $A_{t}$ is assumed to have a unit root, consumption, investment, capital, real wages and output evolve along a stochastic growth path. Once the model is rewritten in terms of detrended variables, we can compute the non-stochastic steady state and employ the partially nonlinear method illustrated in section 2 and appendix A, to approximate the model around the steady state. This delivers a partial nonlinear state space model of the kind described in Shephard (1994).

We conclude the discussion of the model by specifying the vector of observables, completing the state space representation of our model:

$$
\left[\Delta \log Y_{t}, \Delta \log C_{t}, \Delta \log I_{t}, \log L_{t}, \Delta \log \frac{W_{t}}{P_{t}}, \pi_{t}, R_{t}\right],
$$

where $\Delta \log X_{t}$ denotes $\log X_{t}-\log X_{t-1}$.

\section{INFERENCE}

4.1. The Data. We estimate the model using seven series of U.S. quarterly data, as in Levin, Onatski, Williams, and Williams (2005) and Del Negro, Schorfheide, Smets, and Wouters (2004). These series correspond to the vector of observable variables of our model, reported in section 3.6. The sample for our dataset spans from 1954QIII up to 2004QIV. All data are extracted from Haver Analytics database (series mnemonics in parenthesis). Following Del Negro, Schorfheide, Smets, and Wouters (2004), we construct real GDP by diving the nominal series (GDP) by population (LF and LH) and the GDP Deflator (JGDP). Real series for consumption and investment are obtained in the same manner, although consumption corresponds only to personal consumption expenditures of non-durables (CN) and services (CS), while investment is the sum of personal consumption expenditures of durables (CD) and gross private domestic investment (I). Real wages corresponds to nominal compensation per hour in the non-farm business sector (LXNFC) divided by the GDP deflator. Our measure of labor is given by the log of hours of all persons in the non-farm business sector (HNFBN) divided by population. Inflation is measured as the quarterly log difference in the GDP deflator, while for nominal interest rates we use the effective Federal Funds rate. We do not demean or detrend any series.

4.2. Bayesian Inference. Bayesian Markov chain Monte Carlo (MCMC) methods are used to characterize the posterior distribution of the model's structural parameters $(\theta)$, the time varying volatility of the shocks $\left(\left\{\sigma_{t}\right\}_{t=1}^{T}\right)$ and the coefficients of 
the volatility processes $\left(\left[\sigma, \rho_{\sigma}, s^{2}\right]\right)$. Bayesian methods deal efficiently with the high dimension of the parameter space and the nonlinearities of the model, by splitting the original estimation problem into smaller and simpler blocks. In particular, the MCMC algorithm for this paper is carried out in three steps. First, a Metropolis step is used to draw from the posterior of the structural coefficients $\theta$. Drawing the sequence of time varying volatilities $\sigma^{T}$ (conditional on $\theta, \sigma, \rho_{\sigma}$ and $s^{2}$ ) is instead more involved and relies mostly on the method presented in Kim, Shephard, and Chib (1998). It consists of transforming a nonlinear and non-Gaussian state space form in a linear and approximately Gaussian one, which allows the use of simulation smoothers such as Carter and Kohn (1994) or Durbin and Koopman (2002). Simulating the conditional posterior of $\left[\sigma, \rho_{\sigma}, s^{2}\right]$ is standard, since it is the product of independent normal-inverse-Gamma distributions. The details are left to appendix B.

4.3. Priors. As customary when taking DSGE models to the data, we fix a small number of the model parameters to values that are very common in the existing literature. In particular, we set the steady state share of capital income $(\alpha)$ to 0.3 , the quarterly depreciation rate of capital $(\delta)$ to 0.025 and the steady state government spending to GDP ratio to 0.22 , which corresponds to the average share of government spending in total GDP $\left(G_{t} / Y_{t}\right)$ in our sample. Moreover, in order to reduce the number of free parameters, we set all the autoregressive coefficients of the log-volatilities, $\rho_{\sigma}$ 's, to 1 , which reflects the assumption that the volatilities follow geometric random walk processes.

The first three columns of table 1 report our priors for the remaining parameters of the model. While most of these priors are relatively disperse and reflect previous results in the literature, a few of them deserve some further discussion. For all but one persistence parameters we use a Beta prior, with mean 0.5 and standard deviation 0.15. The exception is the autoregressive coefficient of the mark-up shock due to a weak identification problem between this parameter and the one capturing the degree of price indexation. As a result, we imposed a tighter prior on $\rho_{p}$ to avoid convergence problems in our MCMC algorithm.

The priors for the variances of the shocks are Inverse-Gamma distributions with mean and standard deviation equal to 0.15 , with the exception of the investment specific technology shock. In fact, as we will see in the next section, this shock turned out to be (somewhat to our surprise) very important. To be conservative, 
we decided to impose a prior favouring slightly less variation than other shocks. Notice, however, that this prior enters only in the specification of the model without stochastic volatility that we estimate only for comparison.

The priors on the variance $\left(s^{2}\right)$ of the innovations to the log-volatility processes deserve some comment as well, as these coefficients are new in the DSGE literature. We chose an inverse-Gamma prior with mean equal to $0.01^{2}$ for several reasons. First, assuming that the log-volatilities behave as random walks, this parameterization implies an average variation of about 15 percent over our sample of forty years. We regard this as a conservative estimate. Second, in the context of time varying vector autoregressions, Primiceri (2005) has tested several prior specifications and concluded that this value attains the highest marginal likelihood. Nonetheless, we assessed the sensitivity of the estimates to alternative specifications of the prior (especially for the variance of the innovation to the log-volatilities) and found that these modifications had no important influence on the results.

\section{Estimation Results}

5.1. Parameter estimates. The last three columns of table 1 summarize the posterior distribution of the model coefficients, reporting posterior medians, standard deviations and 5th and 95th percentiles computed with the draws. All coefficients estimates are fairly tight and seem for the most part in line with those reported in Del Negro, Schorfheide, Smets, and Wouters (2004) and Levin, Onatski, Williams, and Williams (2005).

One important exception is the wage stickiness parameter $\left(\xi_{w}\right)$, which is lower than previous estimates reported in the literature dealing with inference in DSGE models. In view of the welfare implications of wage rigidity (see, for instance, Levin, Onatski, Williams, and Williams (2005)) these variations in estimates may be important, although we do not explore these issues in the current paper. The estimate of the Calvo stickiness parameters for prices $\left(\xi_{p}\right)$ is approximately equal to $\frac{2}{3}$, which is also a value slightly below those found in other papers. ${ }^{4}$ This number seems still higher than estimates in micro studies (see, for instance, Bils and Klenow (2004)), although the presence of indexation mechanisms (which assures that prices are actually changed in every period) makes the results potentially consistent with the micro evidence on the high frequency of price changes.

\footnotetext{
${ }^{4}$ See Altig, Christiano, Eichenbaum, and Linde (2005) for an example of a model generating an even lower estimate of the price stickiness parameter.
} 
For comparison, table 1 also reports posterior medians, standard deviations, 5th and 95th percentiles of a model estimated with time invariant volatilities. Notice that most of the coefficient estimates are similar to the time varying model, although there are some important exceptions. Most notably, two of the coefficients related to the labor market block of our framework change importantly when stochastic volatility is allowed for. Specifically, the Calvo wage stickiness parameter $\left(\xi_{w}\right)$ drops from 0.71 to 0.38 and the inverse Frisch elasticity of labor supply $(\nu)$ declines as well from 3.8 to 2.5. The higher elasticity of labor supply and the more volatile behavior of wages are compensated by a smoother pattern of the intra-temporal preference shock $\left(\varphi_{t}\right)$, whose autocorrelation coefficient is estimated much higher in the stochastic volatility model. This suggests that not accounting for stochastic volatility might introduce some identification bias in the estimation. ${ }^{5}$

Finally, table 4 shows that the estimates of the fixed coefficients are quite robust to the alternative specification of the monetary policy rule, in which the monetary authority responds to output growth.

5.2. Volatility estimates. Figure 1 presents the plots of the time varying standard deviations for the seven shocks of our model. Notice that the degree of stochastic volatility varies substantially across disturbances. Three of the shocks seem to have relatively constant standard deviations. This is the case for the price mark-up shock $\left(\lambda_{p, t}\right)$, and the two taste shocks $\left(b_{t}\right.$ and $\left.\varphi_{t}\right)$. The evidence is very different for the volatility of the four remaining shocks, which exhibit a very important amount of time variation. The exogenous disturbance showing the highest degree of time varying volatility is the monetary policy shock $\left(\varepsilon_{t}^{M P}\right.$, figure 1a), for which the difference between the lowest and the highest levels of the standard deviation is roughly 500 percent. Observe that the "Volcker episode" 6 is perfectly captured in our estimates, as well as the reduction in the volatility of monetary policy shocks during the Greenspan period.

\footnotetext{
${ }^{5}$ It is worth pointing out that the posterior distribution of the time invariant model is bimodal. The values reported in table 1 are relative to the global maximum. However, there exists a local maximum for which the level of the log-posterior is only slightly lower (just by one point) and the values of the coefficients are much closer to the estimates of the time varying model. Notice also that the time varying model does not exhibit the problem of two modes, suggesting that accounting for stochastic volatility might help to solve some of the identification problems, which are common in this class of models (Canova and Sala (2005)).

6 The "Volcker episode" refers to the high volatility of interest rates in the 1979-1983 period, due to the monetary targeting regime initiated by chaiman Paul Volcker in response to the dramatic rise in U.S. inflation in the 1970s.
} 
Monetary policy shocks are not the only ones exhibiting a clean pattern of time varying volatility. The standard deviation of technology shocks $\left(z_{t}\right.$, figure $\left.1 \mathrm{~b}\right)$ seems to decrease by almost 50 percent in the second part of the sample. This is potentially consistent with the observed reduction in the volatility of GDP in the last two decades, an issue addressed in more detail in the next section. A similar pattern is observed for the volatility of the investment specific technology shock ( $\mu_{t}$, figure 1d) and the government spending shock ( $g_{t}$, figure 1c). Note, however, that between these two shocks the fall in volatility at the beginning of the 1980s seems more dramatic in the case of the investment specific technology shock.

One contribution of our analysis is the ability to quantify how the importance of various shocks has changed over time in generating economic fluctuations. To this end, we analyze the variance decomposition of each series, which will lead us to address the causes of the Great Moderation in the next subsection. We perform the variance decomposition exercise in the following way: for every draw of the parameters and the volatilities of the exogenous disturbances, we construct the implied variances of the (endogenous) observable variables, using the state space representation of the model solution. Then, we re-compute the variances of the observable variables, by sequentially setting to zero the volatility of all disturbances but one, for all time periods. In this way we are able to investigate the contribution of each shock to the variance of the observables. Notice that, since the variances are changing over time, our variance decomposition is a time varying "object" as well. Due to space considerations, we do not present the graph of the variance decomposition for all of the observables. Instead, we present a complete characterization of the variance decomposition for GDP, while for the remaining series we only report the time varying share of the variance explained by selected shocks.

Figure 2 presents the time varying shares of the variance of GDP growth due to each exogenous disturbance. Consistent with Greenwood, Hercowitz, and Krusell (2000) and Fisher (2005), the most important shock in explaining the variability of GDP growth seems to be the investment specific technology shock (figure 2d). Indeed, at least in the first part of the sample, this disturbance explains roughly 40 percent of the variance of GDP growth. Note, however, that the importance of this shock declines over time.

On average, neutral technology and labor preference shocks each explain 20 percent of the variance of GDP. This share seems to remain relatively stable over time for the neutral technology shock (figure 2b), while it increases in the last two 
decades for the disturbances to labor preferences (figure 2f). Other shocks are less central for output. The limited importance of the monetary policy shock (figure $2 a)$ is striking and probably related to the observation that, in this class of models, flexible price output seems to track quite closely actual output (Walsh (2005)), which represents a shortcoming of current sticky price models.

For the remaining series, figure 3 plots the time varying variance shares explained by selected shocks. A major portion of the variance of consumption is explained by the inter-temporal shock to the discount factor (figure 3a). Although not crucial for output, monetary policy and mark-up shocks are each quite important for the volatility of interest rates (figure 3b) and inflation (figure 3c). Moreover, as one would expect, the investment specific technology shock and the labor preference shock explain most of the variability of investment (figure 3d) and hours (figure $3 e$ ) respectively, while the neutral technology shock accounts for about 40 percent of the variance of real wages (figure $3 \mathrm{f}) .^{7}$

Figure 4 plots the model's spectral variance decomposition for output, in deviations from the model's common stochastic trend, driven by neutral technology. We consider periodicities between 8 and 32 quarters. Figure 4 corroborates the evidence on the importance of the investment specific technology shock, suggesting that this disturbance is crucial in explaining output fluctuations at the business cycle frequencies (figure $4 \mathrm{~d}$ ). Note, however, that the labor disutility shock plays also a very important role in this case (figure 4f).

\section{The Great Moderation}

\subsection{The Great Moderation and the role of investment specific technology}

shocks. We now apply our methodology and our results to analyze in greater detail the Great Moderation episode that we have alluded to earlier. In two very influential papers, Kim and Nelson (1999) and McConnell and Perez-Quiros (2000) drew attention to the dramatic reduction in the volatility of U.S. GDP, which has characterized the last two decades relative to the pre-1980s period. ${ }^{8}$ This change seems to be more abrupt than gradual (Kim and Nelson (1999) and Stock and Watson (2002)) and the break date is estimated to approximately correspond to 1984. In our sample, the standard deviation of GDP growth over the 1984-2004 period is almost one half of the standard deviation computed over the 1955-1983

7 The complete set of variance decomposition graphs is available upon request.

8 Stock and Watson (2003b) show a similar pattern for other G7 countries. 
sample. As mentioned, the literature has labeled this phenomenon as the Great Moderation.

A number of hypothesis have been put forward to account for this decline in volatility and exhaustive reviews can be found in Blanchard and Simon (2001) and Stock and Watson $(2002,2003 a)$. Explanations of this phenomenon can be broadly bunched as corresponding to simply good luck, technological progress (particularly in managing inventories) or improvements in the conduct of monetary policy under the Volcker and Greenspan chaimanships. However, several authors have found evidence contrary to the technological progress and improved monetary policy hypotheses (see, for instance, Stock and Watson (2002), Maccini and Pagan (2003) or Ahmed, Levin, and Wilson (2004)).

Therefore, the starting point of the analysis of the Great Moderation undertaken in this paper is the very robust finding of Stock and Watson (2002, 2003a), who conclude that "this reduction in volatility is associated with an increase in the precision of forecasts of output growth" (Stock and Watson (2002), p 42). Notice that our framework is a natural candidate to understand the structural causes of the reduction in forecast errors. In fact, given that our methodology allows for time varying volatilities and is based on a fully-fledged model, it provides an easy interpretation for the structural disturbances hitting the economy.

Figure 5a plots the volatility of GDP growth implied by our model. There are at least two things to notice. First, although the evolution of the standard deviation of GDP growth is very similar to the one obtained from univariate estimates, we notice that the DSGE model somewhat overpredicts the level of the volatility. This problem is common to the time invariant version of the model and is therefore indicative of difficulties in simultaneously matching the levels of persistence, comovements and volatilities observed in the data, even with state of the art DSGE models (Del Negro, Schorfheide, Smets, and Wouters (2004)). Second, nonetheless, the model captures remarkably well the timing and the size of the Great Moderation, despite the abrupt nature of this fall in volatility. Observe that the volatility of GDP growth starts declining around 1981, which is slightly earlier than some estimates provided by the literature using models with discrete structural breaks. This is due to the specification of our time varying volatility model, which tends to smooth out abrupt changes (see, for example, Boivin (2001)).

To assess the role played by each shock in accounting for the Great Moderation, we rely on counterfactual simulations exercises. Our approach consists of using 
our model to simulate the volatility of GDP growth under alternative paths for the volatility of each structural disturbance. This counterfactual simulations can be interpreted as the hypothetical pattern of the volatility of GDP growth in the period 1981-2004, had the standard deviation of that particular structural shock only remained unchanged with respect to the 1980 level. $^{9}$

Figure 6 presents the results of our counterfactual exercises. Our approach gives a very strong conclusion about the causes of the Great Moderation. As evident from figure $6 \mathrm{~d}$, the main explanation for the Great Moderation seems to be the sharp reduction in the volatility of investment specific technology shocks. That is, had the volatility of investment specific technology shocks remained at its 1980 level, then the standard deviation of GDP growth would have been substantially higher than the realized one in the 1981-2004 period.

Finally, it is worth noting that changes in the volatility of the monetary policy shock have had a rather modest effect on the decline in the variance of output (figure 6a). This is the case, despite the fact that the model reproduces quite well the time varying pattern of the standard deviation of interest rates observed in the data (figure $5 \mathrm{~b}$ ).

6.2. The relative price of investment. In our model, investment specific technology shocks can be equivalently interpreted as disturbances to the inverse price of efficient units of investment in terms of consumption goods. ${ }^{10}$ Although this variable is not used in our estimation, data on the price of investment relative to consumption has been used by other authors to proxy for investment specific technology shocks (see, for instance, Greenwood, Hercowitz, and Krusell (1997, 2000) and Fisher (2005)).

In order to verify that the reduction in the volatility of investment specific technology shocks is not somewhat spurious and specific to our model, we rely on data outside our DSGE model and analyze the volatility of this relative price. In particular, we construct the chain-weighted deflators for our components of consumption (non-durables and services) and investment (durables and total private investment) and estimate the standard deviation of its growth rate using a simple 10-year moving window. Figure 7 plots the estimate of the time varying standard deviation and

\footnotetext{
${ }^{9}$ More precisely, we fix the volatility of each shock to the average of the time varying standard deviation for all four quarters in 1980. A longer window does not affect our results.

10 See Fisher (2005) for an explanation of this alternative interpretation.
} 
makes clear that this volatility has sharply decreased in the second part of the postwar sample. Moreover, the timing of the decline corresponds remarkably well with the timing of the Great Moderation. We regard the fact that our model provides a very similar insight (without using any data on the relative price of investment) as a remarkable result.

6.3. Interpretation. What are the main implications of our results? The answer to this question depends on the interpretation of disturbances in DSGE models. Most of the existing literature regards these shocks as genuinely exogenous shifts in tastes, technology and policies. An alternative interpretation, however, is that these disturbances can proxy for features of the economy that we wish to abstract from when writing down our model (Hall (1997) and Chari, Kehoe, and McGrattan (2005)). In particular, Chari, Kehoe, and McGrattan (2005) have recently argued that disturbances similar to our investment specific technology shock might proxy for investment financial frictions. This link becomes evident in models that take into consideration agency costs for the financing of investment, such as Carlstrom and Fuerst (1997) ${ }^{11}$ If we subscribe this view, a natural explanation of the Great Moderation would be based on a reduction in financial frictions.

Interestingly, this purely "theoretical" hypothesis squares remarkably well with the empirical and anecdotal evidence about the expanded access to credit and borrowing for firms and particularly households since the beginning of the 1980s. The mortgage industry underwent substantial financial deregulation in this period, following the passing of the Depository Institutions Deregulation and Monetary Control Act (DIDMCA) in 1980 and the Garn-St Germain Act of 1982. An important component of this transformation was the demise of Regulation $\mathrm{Q}$ which had established a ceiling for banks deposit rates, limiting de facto the amount of bank lending in periods of rising interest rates. Overall, these new laws ignited other developments (such as mortgage securitization) that fostered greater integration between mortgage and capital markets and consequently led to greater availability of mortgage credit at prevailing market interest rates (see, for instance, Hendershott (1990), Dynan, Elmendorf, and Sichel (2005) and Campbell and Hercowitz (2004)).

Since our model is not rich enough to analyze this issue in greater detail, we rely on alternative evidence to support our claim that a reduction in investment

11 See Faia and Monacelli (2004) for an analysis of alternative specifications of agancy costs models and their implications for dynamics in New-Keynesian DSGE models. 
financial frictions-proxied by the decline in variability of our investment specific technology shock-played a predominant role in the Great Moderation. This alternative evidence in support of our hypothesis is summarized in figures 8 and 9 .

Figure 8 plots the time varying standard deviations of consumption, investment and several of their components, obtained using an $\mathrm{AR}(4)$ model with stochastic volatility. Notice that the most drastic reduction in volatility has characterized the time series of investment and particularly residential investment, whose standard deviation has decreased by more than 70 percent. The volatilities of the other components exhibit smoother evolutions with the exception, perhaps, of durable consumption. This is consistent with the sizable reduction in the variability of production in the automobile industry (as detailed in Ramey and Vine (2005)), as it reasonable to expect that the automobile industry would also be quite sensitive to deepening of credit markets (Campbell and Hercowitz (2004)).

Finally, observe that we present alternative series for real investment in equipment and software, depending on whether Gordon (1990)-Cummins and Violante (2002) or NIPA deflators are used to construct these series. This is done in order to asses the robustness of our results to additional quality adjustments in the NIPA deflator for equipment and software, as noted by Greenwood, Hercowitz, and Krusell (1997) and Fisher (2005) in their analysis of investment specific technology shocks. As it is clear from figures $8 \mathrm{f}$ and $8 \mathrm{~h}$, these data considerations are inconsequential for our analysis of volatility.

Further compelling evidence on the role of financial frictions-particularly for residential investment-in explaining the Great Moderation is presented in figure 9 (first column) which plots the spreads between the 30-year fixed mortgage interest rate and the AAA Moody bonds, 10-year and 30-year Treasury constant maturity rates. $^{12}$ The large and volatile spreads of the early 1980s correspond to the end of a system dominated by heavily regulated thrift institutions, in which credit availability was subject to large swings due to fluctuations in deposits (Bradley, Gabriel, and Wohar (1995)). The transition to smaller spreads is commonly associated with the beginning of a more efficient and integrated mortgage market (McCarty and Peach (2002), Dynan, Elmendorf, and Sichel (2005) or Schnure (2005)).

With this observation in mind, next to each series, we also plot an estimate of the time varying standard deviation for each spread, obtained using an AR(4) model

\footnotetext{
12 Our plots of the spreads start in 1978 because data about the 30-year Treasury constant maturity rate are not available before that date.
} 
with stochastic volatility. Three points deserve particular attention: first, all three volatilities decline quite sharply at the beginning of the 1980s; second, the timing of the decline coincides perfectly with the timing of the Great Moderation and, particularly, of the important reduction in the volatility of residential investment already documented (figure 9d). Finally, the timing and the sharpness of the decline in volatility of the mortgage over 30-year Treasury Bills spread (figure 9f) suggests that the turmoil in the mortgage market before the early 1980s was probably due to other factors, beyond the chaos caused by the behavior of inflation and inflation expectations during this period.

To summarize, the sharp decline in the volatility of investment specific technology shocks, as well as the relative price of investment to consumption, matches very well with the empirical evidence on the expanded access to credit and borrowing for firms and especially households since the beginning of the 1980s. Indeed, the Great Moderation is most evident for residential investment, and the timing of this reduction in volatility accords well with developments in the mortgage market that are widely believed to have fostered a decline in financial frictions. We therefore view the development of more elaborate DSGE models, relative to ours, that could shed light on these issues as a worthy endeavor.

6.4. Robustness issues. In this subsection we perform robustness checks on our important finding that the Great Moderation appears to have been driven by the decline in volatility of investment specific technology shocks.

Our focus is on two of the main explanations that have been provided for the Great Moderation: changes in the conduct of monetary policy (Bernanke (2004)) and technological improvement in inventory management (McConnell and PerezQuiros (2000) and Kahn, McConnell, and Perez-Quiros (2002)). To deal with the first issue, we perform a simple experiment which suggests that in the context of this model, the lower variability of U.S. output is difficult to explain when only considering changes in the systematic part of monetary policy. Regarding inventory management, our second exercise is to re-estimate our model using series that abstract from the role of inventories in order to show that the Great Moderation is still evident in this case, albeit in a somewhat less drastic manner. The results of these two exercises (although they echo findings elsewhere using other methods and models) cannot be taken as conclusive evidence against these two hypotheses, which may have played some role in the Great Moderation. Nonetheless, they show that 
when these variants are considered, the decline in the variability of GDP growth is once again largely attributed to a reduction in the volatility of investment specific technology shocks.

6.4.1. Changes in monetary policy. Our strategy to address the importance of the changes in the systematic part of monetary policy consists of estimating our model (without stochastic volatility) on two separate subsamples, 1953-1979:II and 19832004:III. Notice that, following Hanson (2003), we exclude the 1979:III-1982:IV period from the estimation since monetary policy during this period may not be correctly characterized by a Taylor rule. ${ }^{13}$ Table 2 presents posterior modes and standard deviations of the coefficients estimated over these two periods. Observe that there are some differences in the coefficient estimates across subsamples. Consistent with the evidence presented earlier, this is particularly the case for the standard deviations of the shocks. In addition, table 3 highlights that the unconditional standard deviation of output growth in the second subsample relative to the first is 0.52 . In the context of our model this discrepancy can potentially be explained by three different sets of parameters: the monetary policy coefficients, the remaining structural parameters and the standard deviations of the shocks.

With regard to the policy coefficients, notice that, as expected, monetary policy in the second subsample seems to have been more responsive to inflation (Clarida, Gali, and Gertler (2000)). To assess the role of these change in the systematic part of policy on the volatility of output, table 3 presents the relative standard deviation of GDP growth when the coefficients of the Taylor rule estimated in the second subsample replace the corresponding coefficients in the first subsample, leaving all other coefficients unchanged. In order to gauge the possible role of changes in the remaining structural parameters, table 3 also presents the relative volatility of GDP growth when a similar counterfactual exercise is performed by replacing all coefficients (other than the volatilities) from the second sub-sample. Table 3 makes clear that neither changes in the systematic part of monetary policy nor the remaining structural coefficients of the model seem to account for the decline in the volatility of output. This result is in line with Sims and Zha (2004), Hanson (2003), Leduc and Sill (2003), Primiceri (2005), Ahmed, Levin, and Wilson (2004).

\footnotetext{
13 To further check the robustness of this experiment, we have also estimated the model from 1979:III to 2004:III allowing for stochastic volatility in order to capture the large degree of variability of interest rates during this period. Our results are unaffected by this modification.
} 
The split-sample estimates of table 2 are obtained using the priors reported in table 1 for both subsamples. Notice that the prior for the coefficient of the policy response to inflation $\left(\phi_{\pi}\right)$ is a normal distribution with mean equal to 1.7 and standard deviation equal to 0.3. This prior specification puts very low probability on values of $\phi_{\pi}$ smaller than one, which, according to Clarida, Gali, and Gertler (2000), are plausible parameter values for the pre-1980 period. Interest in this case arises from noting that, when $\phi_{\pi}<1$, the model admits multiple (sunspot) equilibria, which can generate arbitrarily high volatility in the macroeconomy. At least in principle, this could potentially explain the larger volatility of GDP growth in the pre-Volcker period.

To assess whether our results are driven by not allowing for indeterminacy, we reestimate the model in the pre-Volcker period using a different prior for the reaction coefficient to inflation. In particular, the new prior density for $\phi_{\pi}$ has a larger standard deviation (equal to 0.7 ) and, hence, puts considerably more weight on the indeterminacy region. Interestingly, our new estimate of the reaction coefficient to inflation remains almost unchanged across priors (first two columns of table 4). In particular, the 90 percent posterior interval is well above one and none of the generated draws from the posterior falls close to the indeterminacy region.

We do not view the absence of indeterminacy in our estimates as surprising. In fact, sunspot equilibria due to an accommodating central bank tend to generate a positive comovement between inflation and real activity in sticky prices models, as forcefully argued by Christiano and Gust (1999). This is clearly at odds with the U.S. experience in the 1970s. As a result, we conclude that in our model, an explanation of the Great Moderation based on indeterminacy seems at odds with the data, while we recognize that there are certainly other models in which an explanation along these lines could be more promising. Similarly, we acknowledge that the role of real time data combined with mismeasurement of the variables entering the Taylor rule may, in smaller models, provide a stronger case for monetary policy as responsible, at least in part, for greater stability after 1984 (see Orphanides and Williams (2005)). However, the validity of this explanation in the context of large scale models like ours has not yet been addressed and remains a topic for future research. 
6.4.2. Changes in inventory management. Regarding the role of inventories in explaining the Great Moderation, we proceed with the rather simple exercise of constructing series of investment and, therefore, output that abstract from inventories. This approach corresponds with the measurement of investment series in some business cycle quantitative studies (for example, Fisher (2005)). Furthermore the rationale for subtracting inventories from output, as opposed to working with the series for inventories themselves, arises from the ambiguity of whether inventories buffer or rather amplify economic fluctuations. ${ }^{14}$ That is, it remains unclear whether an increase in the volatility of inventories would map into a rise or a decline of the volatility of output. Our aim here is simply to check whether when removing inventories the Great Moderation is still evident and, furthermore, whether our conclusions regarding the importance of investment specific technology shocks in accounting for this episode still hold.

Using this new series for investment and output ${ }^{15}$ we re-estimate the model with stochastic volatility over the full sample. Figure 8 presents counterfactual exercises constructed similarly to those reported in section 6.1 , using the new coefficient and volatility estimates. In this case, the moderation in the variability of output growth is still evident although the decline is somewhat more prolonged as opposed to abrupt. Moreover, monetary policy shocks seem to be slightly more important than in the baseline case. Notice, however, that the role of investment specific technology shocks in accounting for the lower volatility of output growth remains for the most part unaltered. This exercise suggests that, while inventories may be important for understanding the sharp drop in the variability of output growth, it would seem that additional explanations are needed to address the Great Moderation (see also Stock and Watson (2002), Maccini and Pagan (2003), Herrera and Pesavento (2005) or Ramey and Vine (2005) for similar conclusions). In this respect, and consistently once again with our previous findings, our results point to the predominant role of investment specific technology shocks in explaining the reduced volatility of the U.S. economy after 1984 .

\footnotetext{
14 Kahn and McConnell (2002), for instance, argue that while in theory inventories should buffer production from fluctuations in sales, in practice the opposite occurs as inventories and sales comove in the same direction.

15 We use nominal fixed investment and accordingly subtract inventories from nominal GDP. Consistent with our previous data, per-capita series are obtained by dividing through with population and the GDP deflator.
} 


\section{Concluding Remarks}

In this paper we have estimated a large scale DSGE model of the U.S. business cycle allowing for the volatility of the structural innovations to change over time. Our results indicate that the volatility of several shocks has changed dramatically in the postwar period. However, the sharp reduction in the standard deviation of GDP growth that has characterized the last twenty years can be explained mostly due to the decline in the variability of a single disturbance: the investment specific technology shock. This crucial disturbance has the equivalent interpretation of a shock to the inverse price of efficient units of investment in terms of consumption goods and, indeed, we also document that this series has exhibited a substantial moderation in its variability, in accordance with the predictions of our model.

Our results provide guidance for future research on the volatility of the U.S. business cycle, suggesting that a fruitful avenue would be to model the variability of disturbances affecting the relative price of investment goods. In particular, it would be useful to extend the DSGE model of this paper in order to provide a more structural interpretation for the sharp reduction observed in the volatility of these shocks. Although beyond the scope of this paper, we note that explanations based on increased access to credit markets (Campbell and Hercowitz (2004)) and a decline in investment financial frictions (like the ones modeled in Bernanke, Gertler, and Gilchrist (1999) or Iacoviello (2005)) are potentially consistent with the decline in the volatility of the relative price of investment.

We conclude by pointing out that the applicability of the modeling framework of this paper goes well beyond the Great Moderation. Indeed, macro-finance applications seem particularly suitable for this methodology. In fact, contrary to standard models with homoskedastic innovations, DSGE models with stochastic volatility as introduced in this paper generate time varying risk premia even with second order approximations of the model solution. More generally, DSGE models with stochastic volatility are appropriate for analyzing the effects of shocks to uncertainty and risk, not only for asset prices, but also for the level of real activity.

\section{Appendix A. Partially nonlinear approximation}

This appendix proofs the validity of the partially nonlinear approximation of the model solution. To simplify the notation, here we work with linearizations (as opposed to log-linearizations). Consider the general class of models described by 
the following system of rational expectations equations:

$$
\begin{aligned}
E_{t}\left[\Phi\left(x_{t+1}, x_{t}, \varepsilon_{t}, \sigma_{t}\right)\right] & =0, \\
\varepsilon_{t} & \sim N(0, I),
\end{aligned}
$$

where each element of $\sigma_{t}$ evolves as in (2.2). Relative to (2.1), (A.1) abstracts from the presence of lagged values of $x$ for simplicity. This is without loss of generality, since the vector of state variables can always be extended to include lags. Let's define

$$
\eta_{t} \equiv \sigma_{t} \circ \varepsilon_{t}
$$

with ' $\circ$ ' denoting the element-by-element product between two vectors. (A.2) can be used to reparameterize (A.1) as follows:

$$
E_{t}\left[\Psi\left(x_{t+1}, x_{t}, \eta_{t}, \sigma_{t}\right)\right]=0 .
$$

Assume that (A.3) admits a unique solution in the neighborhood of the nonstochastic steady state (described by $\Psi(x, x, 0,0)=0$ ). This solution has the form

$$
x_{t}=g\left(\eta_{t}, \sigma_{t}\right) .
$$

To characterize the the first order approximation of (A.4), plug (A.4) into (A.3), obtaining

$$
E_{t}\left[\Psi\left(g\left(\eta_{t+1}, \sigma_{t+1}\right), g\left(\eta_{t}, \sigma_{t}\right), \eta_{t}, \sigma_{t}\right)\right]=0,
$$

and then take a first order Taylor expansion. Since $\sigma_{t}$ and $\varepsilon_{t}$ never enter (A.1) separately (but always as a product), the partial derivative of the function $\Psi(\cdot, \cdot, \cdot, \cdot)$ with respect to its fourth argument is equal to zero, implying a first order approximation of the solution of the form

$$
x_{t}=g_{1} \eta_{t}+o\left(\left\|\eta_{t}, \sigma_{t}\right\|\right)
$$

where the matrix $g_{1}$, is a function of the partial derivatives of the function $\Psi(\cdot, \cdot, \cdot, \cdot)$. Equation (A.5) makes evident that the first order approximation of the model solution as a function of $\eta_{t}$ does not include $\sigma_{t}$ explicitly.

Observe that the more conventional linear approximation of the model solution derived directly from (A.1) would have the form

$$
x_{t}=g_{1} \sigma \circ \varepsilon_{t}+o\left(\left\|\varepsilon_{t}, \sigma_{t}\right\|\right) .
$$


Notice that the norms of both vectors, $\varepsilon_{t}$ and $\sigma_{t}$, are required to approach zero for (A.6) to be an accurate approximation of the model solution. These conditions are sufficient but not necessary for the accuracy of the approximation in (A.5), therefore validating our partially nonlinear approximation.

\section{Appendix B. The estimation algorithm}

B.1. The Standard Case: Homoskedastic Disturbances. For the model without stochastic volatility, the estimation algorithm is simply a random walk Metropolis MCMC procedure, as suggested originally by Schorfheide (2000). To initialize the chains we compute the posterior ordinate for 5,000 draws from the priors, select the ten points attaining the highest posterior density and use a maximization algorithm (Chris Sims' csminwel) to find the posterior mode. Having observed that all chains lead to the same mode, the inverse Hessian at the peak is used as the variance of a proposal density for generating draws with the random walk metropolis. We initialize multiple chains by scaling the inverse Hessian upwards and drawing randomly from a normal centered at the mode. The variance-covariance matrix of the proposal density is adjusted to attain an acceptance rate close to 0.25 , as it is usually suggested. Trace plots, kernel estimates as well as the variants of the potential scale-reduction factors proposed by Brooks and Gelman (1998) are used to gauge the convergence of the algorithm.

B.2. Stochastic Volatility. When the structural shocks exhibit stochastic volatility, this algorithm must be modified to account for inference on the unobserved stochastic volatilities. A Metropolis within Gibbs MCMC algorithm allows us to iteratively draw from the posterior densities of the DSGE model's parameters, stochastic volatilities and associated innovation variances. As discussed below, generating a draw for the stochastic volatilities entails using a normal mixture approximation and sampling a set of latent indicators for the components of this mixture.

To illustrate the steps involved in sampling from the different blocks, let the vector $\theta$ collect all parameters of the DSGE model (other than the standard deviations of the structural disturbances of the time invariant model) and notice that the solution of the linearized DSGE model leads to a state-space representation of the form 


$$
\begin{aligned}
& x_{t}=D y_{t} \\
& y_{t}=A(\theta) y_{t-1}+B(\theta) \eta_{t}
\end{aligned}
$$

where $x_{t}$ and $y_{t}$ represent the observable variables and the endogenous / state variables respectively. (B.2) is the same equation as in (2.3), but we have dropped the "hats" to simplify the notation. As discussed in section A the novelty of our framework is that the vector of structural innovations $\eta_{t}$ (dimension $n \times 1$ ) is allowed to have a time varying variance covariance matrix. Indexing each structural shock by $i$, the stochastic volatilities for each shocks are modelled as

$$
\begin{aligned}
\eta_{i, t} & =\sigma_{i, t} \varepsilon_{i, t} \\
\log \sigma_{i, t} & =\left(1-\rho_{\sigma_{i}}\right) \log \sigma_{i}+\rho_{\sigma_{i}} \log \sigma_{i, t-1}+\nu_{i, t} \\
\varepsilon_{i, t} & \sim N(0,1) \\
\nu_{i, t} & \sim N\left(0, s_{i}^{2}\right) \quad i=1, \ldots, n .
\end{aligned}
$$

Let the vector $h_{t}$, with entry $i$ given by $h_{i, t}=\log \sigma_{i, t}$, collect the $\log$ volatilities for all shocks at time $t$ and stack the whole sample of stochastic volatilities into the matrix $H^{T}=\left[h_{1}, h_{2}, \ldots, h_{t}, \ldots, h_{T}\right]^{\prime}$. Finally, we denote the sample of structural shocks as $\eta^{T}=\left[\eta_{1}, \eta_{2}, \ldots, \eta_{t}, \ldots, \eta_{T}\right]^{\prime}$.

Suppose that the MCMC algorithm has completed iteration $g(>0)$, producing samples $\theta^{(g)}, H^{T,(g)}$ and $V^{(g)}$.of the parameters of interest (individual elements of a vector are indexed by $i$ while $(g)$ indicates the current state of the chain). In iteration $g+1$, the following five steps are used to generate a set of new draws.

B.2.1. Step 1: Draw the structural shocks $\eta^{T,(g+1)}$. In order to generate a new sample of the stochastic volatilities we must first obtain a new draw of the structural shocks. This can be done easily using the efficient simulation smoother for disturbances developed by Durbin and Koopman (2002). The simulation smoother is applied to the state space representation given by (B.1) and (B.2).

B.2.2. Step 3: Draw the stochastic volatilities $H^{T,(g+1)}$. With a draw of $\eta^{T}$ in hand the system of nonlinear measurement equations in (B.3) for each structural shock, can be easily converted in a linear one, by squaring and taking logarithms of every element. Due to the fact that the squared shocks $\eta_{i, t}^{2}$ can be very small, an offset constant is used to make the estimation procedure more robust. Dropping 
the iteration indicators momentarily for ease of notation, this leads to the following approximating state space form:

$$
\begin{aligned}
& \tilde{\eta}_{i, t}=2 h_{i, t}+e_{i, t} \\
& h_{i, t}=h_{i, t-1}+\nu_{i, t} .
\end{aligned}
$$

where $\tilde{\eta}_{i, t}=\log \left[\left(\eta_{i, t}\right)^{2}+\bar{c}\right] ; \bar{c}$ is the offset constant (set to 0.001 ); $e_{i, t}=\log \left(\varepsilon_{i, t}^{2}\right)$. Observe that the $e$ 's and the $\nu$ 's are not correlated. The resulting system has a linear, but non-Gaussian state space form, because the innovations in the measurement equations are distributed as a $\log \chi^{2}(1)$. In order to further transform the system in a Gaussian one, a mixture of normals approximation of the $\log \chi^{2}$ distribution is used, as described in Kim, Shephard, and Chib (1998). Under the assumption of orthogonality across the $\varepsilon$ 's (recall the variance covariance matrix of the $\varepsilon$ 's is the identity matrix) this implies that the variance covariance matrix of the $v$ 's is also diagonal, allowing to use the same (independent) mixture of normals approximation for any for each innovation:

$$
f\left(e_{i, t}\right)=\sum_{k=1}^{K} q_{k} f_{N}\left(e_{i, t} \mid s_{i, t}=k\right), \quad i=1, \ldots, n
$$

where $s_{i, t}$ is the indicator variable selecting which member of the mixture of nor-

mals has to be used at time $t$ for the innovation $i, q_{k}=\operatorname{Pr}\left(s_{i, t}=k\right)$ and $f_{N}(\cdot)$ denotes the pdf of a normal distribution. Kim, Shephard, and Chib (1998) select a mixture of 7 normal densities $(K=7)$ with component probabilities $q_{k}$, means $m_{k}-1.2704$, and variances $r_{k}^{2}, j=1, \ldots, 7$, chosen to match a number of moments of the $\log \chi^{2}(1)$ distribution. For completeness the constants are reported below $\left\{q_{j}, m_{j}, r_{j}^{2}\right\}$ below. ${ }^{16}$

${ }^{16}$ We abstract from the reweighting procedure used in Kim, Shephard, and Chib (1998) to correct the minor approximation error. 


\begin{tabular}{cccc}
\hline \hline$\omega$ & $q_{j}=\operatorname{Pr}(\omega=j)$ & $m_{j}$ & $r_{j}^{2}$ \\
\hline \hline 1 & 0.00730 & -10.12999 & 5.79596 \\
2 & 0.10556 & -3.97281 & 2.61369 \\
3 & 0.00002 & -8.56686 & 5.17950 \\
4 & 0.04395 & 2.77786 & 0.16735 \\
5 & 0.34001 & 0.61942 & 0.64009 \\
6 & 0.24566 & 1.79518 & 0.34023 \\
7 & 0.25750 & -1.08819 & 1.26261 \\
\hline \hline \multicolumn{3}{c}{ Source: Kim, Shephard and Chib (1998). }
\end{tabular}

Conditional on $S^{T,(g)}$, the system has an approximate linear and Gaussian state space form. Therefore a new draw for the complete history of the volatility $H^{T,(g+1)}$ can be obtained recursively with the standard Gibbs sampling for state space forms using, for instance, the forward-backward recursion of Carter and Kohn (1994).

B.2.3. Step 3: Draw the indicators of the mixture approximation $s^{T,(g+1)}$. A new sample of the indicators, $s_{t}^{i,(g+1)}$, for the mixture is obtained conditional on $\eta^{T,(g+1)}$ and $H^{T,(g+1)}$ by independently sampling each from the discrete density defined by $\operatorname{Pr}\left(s_{i, t}^{(g+1)}=j \mid \tilde{\eta}_{i, t}^{(g+1)}, h_{i, t}^{(g+1)}\right) \propto q_{j} f_{N}\left(\tilde{\eta}_{i, t}^{(g+1)} \mid 2 h_{i, t}^{(g+1)}+m_{j}-1.2704, r_{j}^{2}\right), \quad j=1, \ldots, 7$ Consistent with notation above, collect the indicators for which component of the mixture of the normal approximation to use for each structural shock and time period into a stacked matrix $s^{T,(g+1)}=\left[s_{1}^{(g+1)}, s_{2}^{(g+1)}, \ldots, s_{t}^{(g+1)}, \ldots, s_{T}^{(g+1)}\right]^{\prime}$

\section{B.2.4. Step 4: Draw the coefficients of the stochastic volatility processes.}

Having generated a sample $H^{T,(g+1)}$, the vector $\left[\sigma_{i}^{(g+1)}, \rho_{\sigma_{i}}^{(g+1)}, s_{i}^{2}{ }^{(g+1)}\right], i=$ $1, \ldots, n$, can be generated easily from the usual Normal inverse-Gamma distribution.

B.2.5. Step 5: Draw the DSGE parameters $\theta^{(g+1)}$. As in the time invariant algorithm, a new candidate parameter $\theta^{*}$ is drawn from a proposal density. However, in this case, the computation of the likelihood used to construct the probability of acceptance depends on $H^{T,(g+1)}$. More formally the candidate draw is accepted with probability

$$
a=\min \left\{1 ; \frac{\mathcal{L}\left(Y^{T} \mid \theta^{*}, H^{T,(g+1)}\right) \pi\left(\theta^{*}\right)}{\mathcal{L}\left(Y^{T} \mid \theta^{(g)}, H^{T,(g+1)}\right) \pi\left(\theta^{(g)}\right)}\right\},
$$


where $\mathcal{L}(\cdot)$ and $\pi(\cdot)$ denote the likelihood and the prior distribution respectively.

These five steps are repeated $N$ times, across multiple chains. As in the case of the time invariant model, we apply a battery of diagnostics to gauge the convergence of the chains.

\section{REFERENCES}

Ahmed, S., A. Levin, And B. A. Wilson (2004): "Recent U.S. Macroeconomic Stability: Good Policies, Good Practicies, or Good Luck?," The Review of Economics and Statistics, 86(3), $824-832$.

Altig, D., L. J. Christiano, M. Eichenbaum, And J. Linde (2005): "Firm-Specific Capital, Nominal Rigidities and the Business Cycle," NBER Working Paper No. 11034.

An, S., And F. Schorfheide (2005): "Bayesian Analysis of DSGE Models," mimeo, University of Pennsylvania.

Bernanke, B. (2004): "Great Moderation," Speech, February 20, 2004.

Bernanke, B., M. Gertler, And S. Gilchrist (1999): "The Financial Accelerator in a Quantitative Business Cycle Framework," in Handbook of Macroeconomics, ed. by J. B. Taylor, and M. Woodford. North Holland, Amsterdam.

Bernanke, B. S., And I. Mihov (1998): "Measuring Monetary Policy," The Quarterly Journal of Economics, 113, 869-902.

Bils, M., AND P. J. Klenow (2004): "Some Evidence on the Importance of Sticky Prices," Journal of Political Economy, 112(5), 947-985.

Blanchard, O. J., And J. Simon (2001): "The Long and Large Decline in U.S. Output Volatility," Brooking Papers on Economic Activity, 2001-1, 135-174.

Borvin, J. (2001): "The Fed's Conduct of Monetary Policy: Has It Changed and Does It Matter?," mimeo, Columbia University.

Bradley, M. G., S. A. Gabriel, And M. E. Wohar (1995): "The Thrift Crisis, Mortgage-Credit Intermediation, and Housing Activity," Journal of Money, Credit, and Banking, 27(2), 476-97.

Brooks, S. P., And A. Gelman (1998): "General Methods for Monitoring Convergence of Iterative Simulations," Journal of Computational and Graphical Statistics, 7, 434-455.

Calvo, G. (1983): "Staggered Prices in a Utility-Maximizing Framework," Journal of Monetary Economics, 12(3), 383-98.

Campbell, J., And Z. Hercowitz (2004): "The Role of Collateralized Household Debt in Macroeconomic Stabilization," mimeo, Federal Reserve Bank of Chicago.

Canova, F., L. Gambetti, And E. Pappa (2005): "The Structural Dynamics of US Output and Inflation: What Explains the Changes?," mimeo, Bocconi University.

Canova, F., AND L. Sala (2005): "Back to Square One: Identification Issues in DSGE Models," mimeo, Bocconi University, Milan.

Carlstrom, C. T., And T. S. Fuerst (1997): "Agency Costs, Net Worth, and Business Fluctuations: A Computable General Equilibrium Analysis," American Economic Review, 87(5), 893-910. 
Carter, C. K., And R. Kohn (1994): "On Gibbs Sampling for State Space Models," Biometrika, $81(3), 541-553$.

Chari, V., P. J. Kehoe, And E. R. McGrattan (2005): "Business Cycle Accounting," Federal Reserve Bank of Minneapolis, Research Department Staff Report 328.

Chauvet, M., And S. Potter (2001): "Recent Changes in the U.S. Business Cycle," Manchester School of Economics and Social Studies, 69(5), 481-508.

Christiano, L. J., M. Eichenbaum, And C. L. Evans (2005): "Nominal Rigidities and the Dynamic Effect of a Shock to Monetary Policy," The Journal of Political Economy, 113(1), $1-45$.

Christiano, L. J., And C. Gust (1999): "The Great Inflation of the 1970s," mimeo, Northwestern University.

Clarida, R., J. Gali, And M. Gertler (2000): "Monetary Policy Rules and Macroeconomic Stability: Evidence and Some Theory," The Quarterly Journal of Economics, 115(1), 147-180. Cogley, T., And T. J. Sargent (2003): "Drifts and Volatilities: Monetary Policies and Outcomes in the Post WWII U.S.," mimeo, New York University.

Cummins, J. G., And G. L. Violante (2002): "Investment-Specific Technical Change in the US (1947-2000): Measurement and Macroeconomic Consequences," Review of Economic Dynamics, $5(2), 243-284$.

Del Negro, M., F. Schorfheide, F. Smets, And R. Wouters (2004): "On the Fit and Forecasting Performance of New Keynesian Models," Federal Reserve Bank of Atlanta Working Paper No. 2004-37.

Durbin, J., And S. J. Koopman (2002): "A Simple and Efficient Simulation Smoother for State Space Time Series Analysis," Biometrika, 89(3), 603-616.

Dynan, K. E., D. W. Elmendorf, And D. E. Sichel (2005): "Can Finacial Innovation Explain the Reduced Volatility of Economic Activity?," in Carnegie-Rochester Conference Series on Public Policy, ed. by B. McCallum, and C. I. Plosser.

Erceg, C. J., D. W. Henderson, And A. T. Levin (2000): "Optimal Monetary Policy with Staggered Wage and Price Contracts," Journal of Monetary Economics, 46(2), 281-313.

Faia, E., AND T. Monacelli (2004): "Optimal Interest Rate Rules Rules,Asset Prices and Credit Frictions," mimeo, Universitat Pompeu Fabra.

Fernandez-Villaverde, J., And J. Rubio-Ramirez (2004): "Estimating Nonlinear Dynamic Equilibrium Economies: A Likelihood Approach," mimeo, University of Pennsylvania.

Fisher, J. D. M. (2005): "The Dynamic Effect of Neutral and Investment-Specific Technology Shocks," mimeo, Federal Reserve Bank of Chicago.

Gordon, R. J. (1990): The Measurement of Durable Goods Prices. University of Chicago Press, Chicago, IL.

Greenwood, J., Z. Hercowitz, And P. Krusell (1997): "Long Run Implications of InvestmentSpecific Technological Change," American Economic Review, 87(3), 342-362.

Greenwood, J., Z. Hercowitz, And P. Krusell (2000): "The role of investment-specific technological change in the business cycle," European Economic Review, 44(1), 91-115.

HALl, R. E. (1997): "Macroeconomic Fluctuations and the Allocation of Time," Journal of Labor Economics, 15(2), 223-250. 
Hanson, M. (2003): "Varying Monetary Policy Regimes: A Vector Autoregressive Investigation," mimeo, Wesleyan University.

Hendershott, P. H. (1990): "The Market for Home Mortgage Credit: Recent Changes and Future Prospects," NBER Working Paper no. 3548.

Herrera, A. M., And E. Pesavento (2005): "The Decline in U.S. Output Volatility: Structural Changes and Inventory Investment," Journal of Business and Economic Statistics, forthcoming. IAcoviello, M. (2005): "House Prices, Borrowing Constraints and Monetary Policy in the Business Cycle," American Economic Review, 95(3), 739-764.

Ireland, P. N. (2004): "Technology Shocks in the New Keynesian Model," The Review of Economics and Statistics, 86(4), 923-936.

Kahn, J. A., AND M. M. McConnell (2002): "Has Inventory Volatility Returned? A Look at the Current Cycle," Federal Reserve Bank of New York Current Issues in Economics and Finance, 8(5), 1-6.

Kahn, J. A., M. M. McConnell, And G. Perez-Quiros (2002): "On the Causes of the Increased Stability of the U.S. Economy," Federal Reserve Bank of New York Economic Policy Review, $8(1), 183-202$.

Kim, C.-J., And C. R. Nelson (1999): "Has the U.S. Economy Become More Stable? A Bayesian Approach Based on a Markov-Switching Model of the Business Cycle," The Review of Economics and Statistics, 81, 608-616.

Kim, S., N. Shephard, AND S. Chib (1998): "Stochastic Volatility: Likelihood Inference and Comparison with ARCH Models," The Review of Economic Studies, 65(3), 361-393.

Laforte, J.-P. (2005): "DSGE Models and Heteroskedasticity: A Markov-Switching Approach," mimeo, Board of Governors of the Federal Reserve System.

Leduc, S., AND K. Sill (2003): "Monetary Policy, Oil Shocks, and TFP: Accounting for the Decline in U.S. Volatility," Federal Reserve Bank of Philadelphia Research Working Paper no. $03-22$.

Levin, A. T., A. Onatski, J. C. Williams, And N. Williams (2005): "Monetary Policy Under Uncertainty in Micro-Founded Macroeconometric Models," in NBER Macroeconomics Annual. LuCCA, D. O. (2005): "Resuscitating Time to Build," mimeo, Northwestern University.

Maccini, L. J., AND A. PAGAn (2003): "Explaining the Role of Inventories in the Business Cycle," mimeo, Johns Hopkins University.

McCarty, J., And R. W. Peach (2002): "Monetary Policy Transmission to Residential Investment," Federal Reserve Bank of New York Economic Policy Review, 8(1), 139-158.

McConnell, M. M., And G. Perez-Quiros (2000): "Output Fluctuations in the United States: What Has Changed Since the Early 1980's," American Economic Review, 90(5), 1464-1476.

Orphanides, A., And J. C. Williams (2005): "The Decline of Activist Stabilization Policy: Natural Rate Misperceptions, Learning, and Expectations," Journal of Economic Dynamics and Control, 29, 1927-1950.

Primiceri, G. E. (2005): "Time Varying Structural Vector Autoregressions and Monetary Policy," The Review of Economic Studies, 72, 821-852.

Ramey, V. A., AND D. J. Vine (2005): "Declining Volatility in the U.S. Automobile Industry," mimeo, University of California, San Diego. 
Rotemberg, J. J., And M. Woodford (1997): "An Optimization-Based Econometric Model for the Evaluation of Monetary Policy," NBER Macroeconomics Annual, 12, 297-346.

Schnure, C. (2005): "Boom and Bust Cycles in Housing: The Changing Role of Financial Structure," IMF Working Paper no. 200.

Schorfheide, F. (2000): "Loss-Function Based Evaluation of DSGE Models," Journal of Applied Econometrics, 15, 645-670.

Shephard, N. (1994): "Partial Non-Gaussian State Space," Biometrika, 81, 115-131.

Sims, C. A., AND T. Zha (2004): "Were There Regime Switches in US Monetary Policy?," mimeo, Princeton University.

Smets, F., And R. Wouters (2003): "An Estimated Stochastic Dynamic General Equilibrium Model of the Euro Area," Journal of the European Economic Association, 1(5), 1123-1175.

Stock, J. H., AND M. W. WAtson (2002): "Has the Business Cycle Changed and Why?," NBER working paper no. 9127.

- (2003a): "Has the Business Cycle Changed? Evidence and Explanations," mimeo, Princeton University.

(2003b): "Understanding Changes in International Business Cycle Dynamics," mimeo, Princeton University.

Walsh, C. E. (2005): "Comments on "Monetary Policy Under Uncertainty in Micro-Founded Macroeconometric Models," by A. Levin, A. Onatski, J. Williams and N. Williams," in NBER Macroeconomics Annual.

Woodford, M. (2003): Interest and Prices: Foundations of a Theory of Monetary Policy. Princeton University Press, Princeton, NJ.

Federal Reserve Board

Northwestern University AND NBER 
Table 1: Prior densities and posterior estimates with and without stochastic volatility

\begin{tabular}{|c|c|c|c|c|c|c|c|c|c|c|}
\hline \multirow[b]{2}{*}{ Coefficient } & \multirow[b]{2}{*}{ Description } & \multicolumn{3}{|c|}{ Prior } & \multicolumn{3}{|c|}{ Posterior 2/ } & \multicolumn{3}{|c|}{ Posterior with Stochastic Volatility $3 /$} \\
\hline & & $\begin{array}{c}\text { Prior } \\
\text { Density 1/ }\end{array}$ & Mean & Std & Median & Std & {$[5,95]$ Prob } & Median & Std & {$[5,95]$ Prob } \\
\hline$l_{p}$ & Price indexation & B & 0.5 & 0.15 & 0.149 & 0.059 & {$[0.072,0.263]$} & 0.288 & 0.091 & {$[0.158,0.4529]$} \\
\hline$l_{w}$ & Wage indexation & B & 0.5 & 0.15 & 0.11 & 0.031 & {$[0.064,0.164]$} & 0.134 & 0.035 & {$[0.081,0.197]$} \\
\hline$\gamma$ & SS technology growth rate & $\mathrm{N}$ & 0.5 & 0.025 & 0.425 & 0.024 & {$[0.39,0.46]$} & 0.4344 & 0.023 & {$[0.4,0.47]$} \\
\hline$h$ & Consumption habit & B & 0.5 & 0.1 & 0.809 & 0.03 & {$[0.759,0.864]$} & 0.748 & 0.027 & {$[0.705,0.793]$} \\
\hline$\lambda_{p}$ & SS mark-up goods prices & $\mathrm{N}$ & 0.15 & 0.05 & 0.243 & 0.038 & {$[0.18,0.304]$} & 0.218 & 0.034 & {$[0.161,0.275]$} \\
\hline$\lambda_{w}$ & SS mark-up wages & $\mathrm{N}$ & 0.15 & 0.05 & 0.127 & 0.046 & {$[0.054,0.207]$} & 0.171 & 0.038 & {$[0.114,0.241]$} \\
\hline$L^{s s}(\log )$ & SS leisure & $\mathrm{N}$ & 396.83 & 0.5 & 397.218 & 0.451 & {$[396.507,397.986]$} & 396.799 & 0.479 & [ $396.045,397.624$ ] \\
\hline$\pi$ & SS quarterly inflation & $\mathrm{N}$ & 0.5 & 0.1 & 0.578 & 0.098 & {$[0.415,0.735]$} & 0.712 & 0.056 & {$[0.625,0.81]$} \\
\hline$r$ & SS real interest rate & $\mathrm{N}$ & 0.5 & 0.1 & 0.997 & 0.073 & {$[0.876,1.117]$} & 0.996 & 0.067 & {$[0.89,1.114]$} \\
\hline$v$ & Inverse Frisch labor & G & 2 & 0.75 & 3.856 & 0.914 & {$[2.598,5.618]$} & 2.423 & 0.759 & {$[1.57,4.036]$} \\
\hline$\xi_{p}$ & Calvo prices & B & 0.75 & 0.1 & 0.784 & 0.023 & {$[0.745,0.821]$} & 0.681 & 0.027 & {$[0.637,0.725]$} \\
\hline$\xi_{w}$ & Calvo wages & B & 0.75 & 0.1 & 0.718 & 0.051 & {$[0.619,0.784]$} & 0.379 & 0.051 & {$[0.302,0.472]$} \\
\hline$\chi$ & Elasticity capital utilization costs & G & 5 & 1 & 7.136 & 1.104 & {$[5.552,9.133]$} & 7.328 & 1.050 & {$[5.773,9.222]$} \\
\hline$S^{\prime \prime}$ & Investment adjustment costs & $\mathrm{N}$ & 4 & 1.5 & 2.051 & 0.586 & {$[1.331,3.244]$} & 2.447 & 0.490 & {$[1.702,3.338]$} \\
\hline$\Phi_{p}$ & Taylor rule inflation & $\mathrm{N}$ & 1.7 & 0.3 & 2.014 & 0.144 & {$[1.804,2.275]$} & 2.503 & 0.184 & {$[2.225,2.832]$} \\
\hline$\Phi_{y}$ & Taylor rule output & G & 0.125 & 0.1 & 0.072 & 0.014 & {$[0.05,0.097]$} & 0.024 & 0.011 & {$[0.008,0.045]$} \\
\hline
\end{tabular}

Notes:

Calibrated coefficients: labor share $(\alpha)$ at 0.3 , depreciation rate $(\delta)$ is 0.025 , g at $1 / 0.77$ which implies a SS government share of 0.22

Relative to the text, $\gamma$ is expressed in percentage points, while $\pi$ and $\mathrm{r}$ are expressed as net rates, in percentage points. Finally, the standard deviations of the innovations are also scaled by 100 for the estimation. All these changes are reflected in the specification of the priors.

1/ N stands for Normal, B Beta, G Gamma and I Inverted-Gammal distribution

2/ Median, standard deviations and posterior percentiles of 110,000 draws from the Random Walk metropolis algorithm for the model without stochastic volatility. We discard the initial 50,000 draws.

3/ Median, standard deviations and posterior percentiles of 120,000 draws from the Random Walk metropolis within Gibbs algorithm for the model with stochastic volatility. We discard the initial 50,000 
Table 1 (continued): Prior densities and posterior estimates with and without stochastic volatility

\begin{tabular}{|c|c|c|c|c|c|c|c|c|c|c|}
\hline \multirow[b]{2}{*}{ Coefficient } & \multirow[b]{2}{*}{ Description } & \multicolumn{3}{|c|}{ Prior } & \multicolumn{3}{|c|}{ Posterior 2/ } & \multicolumn{3}{|c|}{ Posterior with Stochastic Volatility $3 /$} \\
\hline & & $\begin{array}{c}\text { Prior } \\
\text { Density 1/ }\end{array}$ & Mean & Std & Median & Std & {$[5,95]$ Prob } & Median & Std & {$[5,95]$ Prob } \\
\hline$\rho_{\mu}$ & Investment specific technology & B & 0.5 & 0.15 & 0.909 & 0.028 & {$[0.859,0.949]$} & 0.831 & 0.036 & {$[0.772,0.888]$} \\
\hline$\rho_{\lambda}$ & Mark-up & B & 0.8 & 0.1 & 0.876 & 0.036 & {$[0.81,0.925]$} & 0.908 & 0.029 & {$[0.854,0.95]$} \\
\hline$\rho_{\varphi}$ & Labor disutility & B & 0.5 & 0.15 & 0.489 & 0.07 & {$[0.379,0.609]$} & 0.924 & 0.033 & {$[0.857,0.964]$} \\
\hline$\rho_{b}$ & Intertemporal preference & B & 0.5 & 0.15 & 0.822 & 0.051 & {$[0.716,0.884]$} & 0.822 & 0.042 & {$[0.745,0.883]$} \\
\hline$\sigma_{r}$ & Monetary policy & I & 0.15 & 0.15 & 0.254 & 0.014 & {$[0.232,0.28]$} & & & \\
\hline$\sigma_{z}$ & Technology growth & I & 0.15 & 0.15 & 1.097 & 0.057 & {$[1.006,1.192]$} & & & \\
\hline$\sigma_{g}$ & Government spending & I & 0.15 & 0.15 & 0.553 & 0.035 & {$[0.501,0.615]$} & & & \\
\hline$\sigma_{\mu}$ & Investment specific technology & I & 0.1 & 0.1 & 0.136 & 0.021 & {$[0.108,0.178]$} & & & \\
\hline$\sigma_{\lambda}$ & Mark-up & I & 0.15 & 0.15 & 0.096 & 0.011 & {$[0.08,0.115]$} & & & \\
\hline$\sigma_{\varphi}$ & Labor disutility & I & 0.15 & 0.15 & 0.988 & 0.283 & {$[0.587,1.52]$} & & & \\
\hline$\sigma_{b}$ & Intertemporal preference & I & 0.15 & 0.15 & 0.55 & 0.202 & {$[0.387,1.083]$} & & & \\
\hline
\end{tabular}

Notes:

Calibrated coefficients: labor share $(\alpha)$ at 0.3 , depreciation rate $(\delta)$ is $0.025, \mathrm{~g}$ at $1 / 0.77$ which implies a SS government share of 0.22

Relative to the text, $\gamma$ is expressed in percentage points, while $\pi$ and $r$ are expressed as net rates, in percentage points. Finally, the standard deviations of the innovations are also scaled by 100 for the estimation. All these changes are reflected in the specification of the priors.

1/ N stands for Normal, B Beta, G Gamma and I Inverted-Gammal distribution

2/ Median, standard deviations and posterior percentiles of 110,000 draws from the Random Walk metropolis algorithm for the model without stochastic volatility. We discard the initial 50,000 draws.

3/ Median, standard deviations and posterior percentiles of 120,000 draws from the Random Walk metropolis within Gibbs algorithm for the model with stochastic volatility. We discard the initial 50,000 
Table 2: Posterior estimates on Split Sample (without stochastic volatility)

\begin{tabular}{|c|c|c|c|c|c|}
\hline \multirow[b]{2}{*}{ Coefficient } & \multirow[b]{2}{*}{ Description } & \multicolumn{2}{|c|}{$\begin{array}{c}\text { Posterior } \\
\text { Sample I: 1954q3 - 1979q3 } \\
\end{array}$} & \multicolumn{2}{|c|}{$\begin{array}{c}\text { Posterior } \\
\text { Sample II: } 1984 q 1 \text { - 2004q4 } \\
\end{array}$} \\
\hline & & Mode & Std & Mode & Std \\
\hline$l_{p}$ & Price indexation & 0.218 & 0.088 & 0.178 & 0.073 \\
\hline$l_{w}$ & Wage indexation & 0.094 & 0.031 & 0.410 & 0.075 \\
\hline$\gamma$ & SS technology growth rate & 0.461 & 0.025 & 0.476 & 0.024 \\
\hline$h$ & Consumption habit & 0.817 & 0.032 & 0.688 & 0.041 \\
\hline$\lambda_{p}$ & SS mark-up goods prices & 0.180 & 0.004 & 0.122 & 0.039 \\
\hline$\lambda_{w}$ & SS mark-up wages & 0.150 & 0.002 & 0.178 & 0.009 \\
\hline$L^{s s}(\log )$ & SS leisure & 397.072 & 0.454 & 396.941 & 0.486 \\
\hline$\pi$ & SS quarterly inflation & 0.576 & 0.115 & 0.646 & 0.059 \\
\hline$r$ & SS real interest rate & 0.734 & 0.089 & 0.731 & 0.066 \\
\hline$v$ & Inverse Frisch labor & 2.270 & 0.738 & 1.723 & 0.566 \\
\hline$\xi_{p}$ & Calvo prices & 0.708 & 0.046 & 0.721 & 0.034 \\
\hline$\xi_{w}$ & Calvo wages & 0.626 & 0.084 & 0.350 & 0.073 \\
\hline$\chi$ & Elasticity capital utilization costs & 6.014 & 1.814 & 6.180 & 1.016 \\
\hline$S^{\prime \prime}$ & Investment adjustment costs & 0.814 & 0.227 & 1.875 & 0.544 \\
\hline$\Phi_{p}$ & Taylor rule inflation & 1.644 & 0.099 & 2.386 & 0.170 \\
\hline$\Phi_{y}$ & Taylor rule output & 0.057 & 0.015 & 0.031 & 0.016 \\
\hline$\rho_{r}$ & Taylor rule smoothing & 0.787 & 0.038 & 0.815 & 0.023 \\
\hline$\rho_{z}$ & Technology growth & 0.306 & 0.081 & 0.321 & 0.071 \\
\hline$\rho_{g}$ & Government spending & 0.922 & 0.022 & 0.965 & 0.011 \\
\hline$\rho_{\mu}$ & Investment specific technology & 0.911 & 0.041 & 0.847 & 0.041 \\
\hline$\rho_{\lambda}$ & Mark-up & 0.893 & 0.035 & 0.902 & 0.040 \\
\hline$\rho_{\varphi}$ & Labor disutility & 0.515 & 0.145 & 0.919 & 0.041 \\
\hline$\rho_{b}$ & Intertemporal preference & 0.508 & 0.143 & 0.833 & 0.050 \\
\hline$\sigma_{r}$ & Monetary policy & 0.234 & 0.027 & 0.153 & 0.013 \\
\hline$\sigma_{z}$ & Technology growth & 1.198 & 0.143 & 0.727 & 0.061 \\
\hline$\sigma_{g}$ & Government spending & 0.700 & 0.060 & 0.438 & 0.035 \\
\hline$\sigma_{\mu}$ & Investment specific technology & 0.085 & 0.013 & 0.061 & 0.011 \\
\hline$\sigma_{\lambda}$ & Mark-up & 0.142 & 0.035 & 0.102 & 0.017 \\
\hline$\sigma_{\varphi}$ & Labor disutility & 0.693 & 0.188 & 0.246 & 0.037 \\
\hline$\sigma_{b}$ & Intertemporal preference & 0.881 & 0.249 & 0.202 & 0.039 \\
\hline
\end{tabular}

Calibrated coefficients: labor share $(\alpha)$ at 0.3 , depreciation rate $(\delta)$ is $0.025, \mathrm{~g}$ at $1 / 0.77$ which implies a SS government share of 0.22

Relative to the text, $\gamma$ is expressed in percentage points, while $\pi$ and $\mathrm{r}$ are expressed as net rates, in percentage points. Finally, the standard deviations of the innovations are also scaled by 100 for the estimation. All these changes are reflected in the specification of the priors.

Prior distributions are identical to those reported in Table 1. 


\section{Table 3: Model implied relative standard deviations for output Split sample estimates and counterfactuals}

A

B

Sample I : 1954q3$1979 q 3$

Sample II : 1984q1 $2004 q 4$

Sample I: monetary policy coefficients Sample II 1/
D

Std only Sample I; all other coefficients Sample II $2 /$

Std of output

(relative to std sample I)

1

0.526

1.026

1.114

1/ All coefficients and standard deviations at median estimates for sample I, but replace coefficients of the Taylor rule and the mean of inflation with median estimates for sample II.

2/ Standard deviations at median estimates for sample I, while all other coefficients are at their median estimates for sample II. 
Table 4: Posterior estimates (without stochastic volatility) based on alternative prior and output growth specification for the Taylor Rule

\begin{tabular}{|c|c|c|c|c|c|c|c|}
\hline \multirow[b]{2}{*}{ Coefficient } & \multirow[b]{2}{*}{ Description } & \multicolumn{2}{|c|}{$\begin{array}{c}\text { Sample I: } 1954 q 3 \text { - 1979q3 } \\
\text { Looser prior on } \Phi p \text {, Taylor } \\
\text { Rule Inflation 1/ } \\
\text { Posterior } \\
\end{array}$} & \multicolumn{2}{|c|}{$\begin{array}{c}\text { Full Sample } \\
\text { Output growth in Taylor } \\
\text { Rule } / 2 \\
\\
\text { Posterior } \\
\end{array}$} & \multicolumn{2}{|c|}{$\begin{array}{c}\text { Full Sample } \\
\text { Output growth in Taylor } \\
\text { Rule } / 2 \\
\text { Posterior with Stochastic } \\
\text { Volatility } \\
\end{array}$} \\
\hline & & Median & Std & Median & Std & Median & Std \\
\hline$l_{p}$ & Price indexation & 0.218 & 0.086 & 0.141 & 0.053 & 0.221 & 0.071 \\
\hline$l_{w}$ & Wage indexation & 0.094 & 0.032 & 0.096 & 0.032 & 0.084 & 0.024 \\
\hline$\gamma$ & SS technology growth rate & 0.460 & 0.025 & 0.448 & 0.024 & 0.436 & 0.022 \\
\hline$h$ & Consumption habit & 0.817 & 0.011 & 0.780 & 0.028 & 0.740 & 0.031 \\
\hline$\lambda_{p}$ & SS mark-up goods prices & 0.170 & 0.005 & 0.295 & 0.006 & 0.235 & 0.035 \\
\hline$\lambda_{w}$ & SS mark-up wages & 0.141 & 0.002 & 0.113 & 0.002 & 0.120 & 0.039 \\
\hline$L^{s s}(\log )$ & SS leisure & 397.080 & 0.447 & 396.780 & 0.482 & 396.288 & 0.419 \\
\hline$\pi$ & SS quarterly inflation & 0.576 & 0.095 & 0.838 & 0.059 & 0.755 & 0.050 \\
\hline$r$ & SS real interest rate & 0.730 & 0.079 & 0.939 & 0.068 & 0.950 & 0.056 \\
\hline$v$ & Inverse Frisch labor & 2.253 & 0.558 & 2.838 & 0.887 & 2.582 & 0.705 \\
\hline$\xi_{p}$ & Calvo prices & 0.706 & 0.019 & 0.783 & 0.023 & 0.746 & 0.028 \\
\hline$\xi_{w}$ & Calvo wages & 0.622 & 0.026 & 0.769 & 0.039 & 0.483 & 0.046 \\
\hline$\chi$ & Elasticity capital utilizatior & 6.022 & 1.019 & 7.029 & 2.187 & 7.696 & 0.981 \\
\hline$S^{\prime \prime}$ & Investment adjustment cos & 0.796 & 0.166 & 1.212 & 0.349 & 3.091 & 0.752 \\
\hline$\Phi_{p}$ & Taylor rule inflation & 1.625 & 0.121 & 2.224 & 0.133 & 2.735 & 0.163 \\
\hline$\Phi_{y}$ & Taylor rule output & 0.057 & 0.001 & 0.802 & 0.131 & 0.615 & 0.095 \\
\hline
\end{tabular}

Notes:
Calibrated coefficients: labor share $(\alpha)$ at 0.3 , depreciation rate $(\delta)$ is $0.025, \mathrm{~g}$ at $1 / 0.77$ which implies a SS government share of 0.22

Calibrated coefficients: labor share ( $\alpha$ at 0.3 , depreciation rate $(\delta)$ is $0.025, \mathrm{~g}$ at $1 / 0.77$ which implies a SS government share of 0.22
Relative to the text $\gamma$ is expressed in percentage points, while $\pi$ and $\mathrm{r}$ are expressed as net rates, in percentage points. Finally, the standard deviations of the innovations are also scaled by 100 for the estimation. All these changes are reflected in the specification of the priors.

Except for the coefficients of the Taylor rule, all other priors are identical to those in Table $1 /$

1/ Prior for $\Phi$ p is Normal $(1.7,0.7)$ to provide greater prior mass to the region of indeterminacy. Prior for $\Phi y$ is $\mathrm{N}(0.125,0.1)$ as in Table 1 .

2/ Prior for $\Phi$ is Normal $(1.7,0.3)$ as in Table 1. Prior for $\Phi y$ is $\mathrm{N}(0.5,0.3)$ and in terms of output growth. 
Table 4 (continued): Posterior estimates (without stochastic volatility) based on alternative prior and output growth specification for the Taylor Rule

\begin{tabular}{|c|c|c|c|c|c|c|c|}
\hline \multirow[b]{2}{*}{ Coefficient } & \multirow[b]{2}{*}{ Description } & \multicolumn{2}{|c|}{$\begin{array}{c}\text { Sample I: } 1954 q 3 \text { - 1979q3 } \\
\text { Looser prior on } \Phi p \text {, Taylor } \\
\text { Rule Inflation 1/ } \\
\text { Posterior }\end{array}$} & \multicolumn{2}{|c|}{$\begin{array}{c}\text { Full Sample } \\
\text { Output growth in Taylor } \\
\text { Rule } / 2 \\
\text { Posterior } \\
\end{array}$} & \multicolumn{2}{|c|}{$\begin{array}{c}\text { Full Sample } \\
\text { Output growth in Taylor } \\
\text { Rule } / 2 \\
\text { Posterior with Stochastic } \\
\text { Volatility } \\
\end{array}$} \\
\hline & & Median & Std & Median & Std & Median & Std \\
\hline$\rho_{r}$ & Taylor rule smoothing & 0.784 & 0.030 & 0.833 & 0.017 & 0.861 & 0.014 \\
\hline$\rho_{z}$ & Technology growth & 0.308 & 0.059 & 0.232 & 0.054 & 0.294 & 0.051 \\
\hline$\rho_{g}$ & Government spending & 0.922 & 0.024 & 0.984 & 0.001 & 0.982 & 0.006 \\
\hline$\rho_{\mu}$ & Investment specific techno & 0.912 & 0.027 & 0.888 & 0.022 & 0.803 & 0.034 \\
\hline$\rho_{\lambda}$ & Mark-up & 0.891 & 0.035 & 0.886 & 0.036 & 0.858 & 0.041 \\
\hline$\rho_{\varphi}$ & Labor disutility & 0.509 & 0.048 & 0.579 & 0.063 & 0.851 & 0.063 \\
\hline$\rho_{b}$ & Intertemporal preference & 0.504 & 0.059 & 0.703 & 0.064 & 0.786 & 0.053 \\
\hline$\sigma_{r}$ & Monetary policy & 0.234 & 0.019 & 0.251 & 0.015 & & \\
\hline$\sigma_{z}$ & Technology growth & 1.193 & 0.082 & 1.113 & 0.056 & & \\
\hline$\sigma_{g}$ & Government spending & 0.701 & 0.058 & 0.570 & 0.035 & & \\
\hline$\sigma_{\mu}$ & Investment specific techno & 0.084 & 0.006 & 0.115 & 0.016 & & \\
\hline$\sigma_{\lambda}$ & Mark-up & 0.143 & 0.006 & 0.104 & 0.011 & & \\
\hline$\sigma_{\varphi}$ & Labor disutility & 0.683 & 0.042 & 1.129 & 0.301 & & \\
\hline$\sigma_{b}$ & Intertemporal preference & 0.880 & 0.050 & 0.468 & 0.120 & & \\
\hline
\end{tabular}

Notes:
Calibrated coefficients: labor share $(\alpha)$ at 0.3 , depreciation rate $(\delta)$ is $0.025, \mathrm{~g}$ at $1 / 0.77$ which implies a SS government share of 0.22

Relative to the text, $\gamma$ is expressed in percentage points, while $\pi$ and $\mathrm{r}$ are expressed as net rates, in percentage points. Finally, the standard deviations of the innovations are also scaled by 100 for the estimation. All these changes are reflected in the specification of the priors.

Except for the coefficients of the Taylor rule, all oher priors are identical to those in Table 1

Prior for $\Phi y$ is $\mathrm{N}(0.125,0.1)$ as in Table 1 .

2/ Prior for $\Phi$ is $\mathrm{Normal}(1.7,0.3)$ as in Table 1. Prior for $\Phi \mathrm{y}$ is $\mathrm{N}(0.5,0.3)$ and in terms of output growth. 
Figure 1: Stochastic Volatility of the DSGE Model Shocks

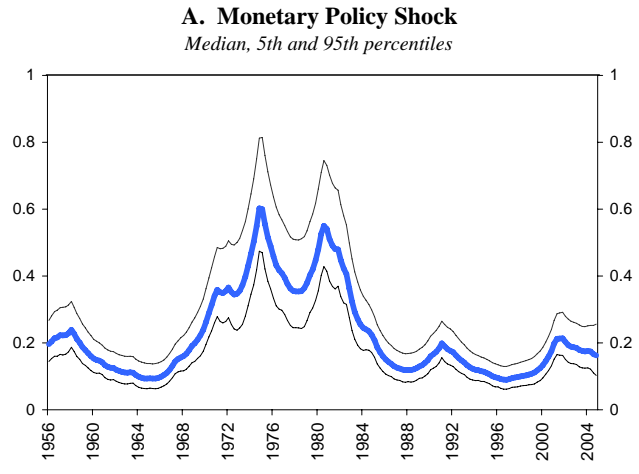

C. Government Spending Shock Median, 5th and 95th percentiles

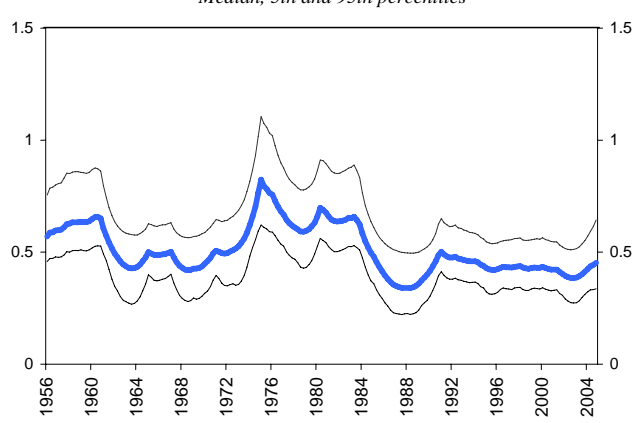

E. Mark-up Shock

Median, 5th and 95th percentiles

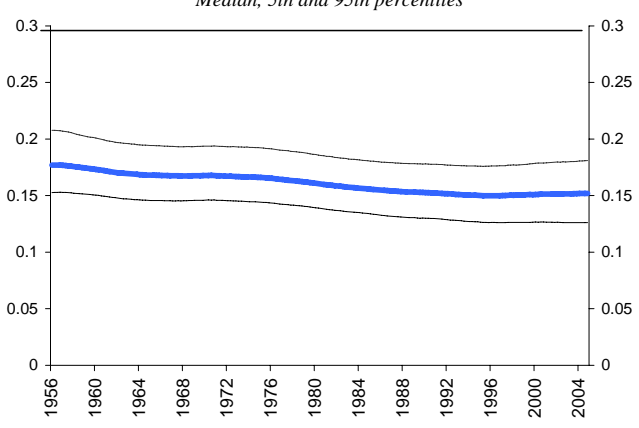

G. Intertemporal Preference Shock

Median, 5th and 95th percentiles

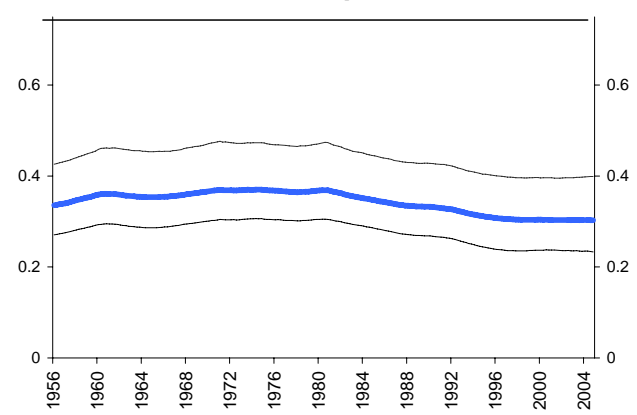

B. Technology Shock Median, 5th and 95th percentiles

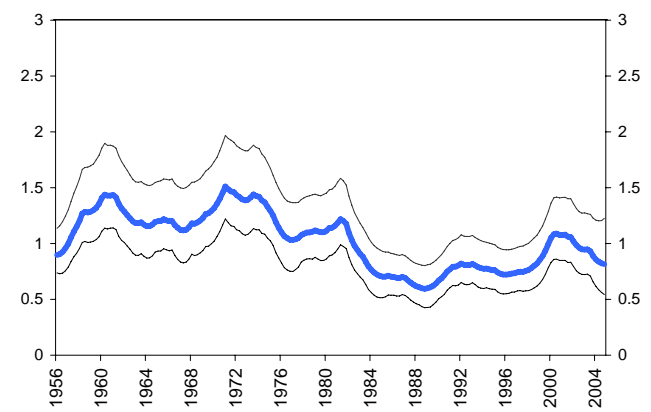

D. Investment Specific Technology Shock Median, 5th and 95th percentiles

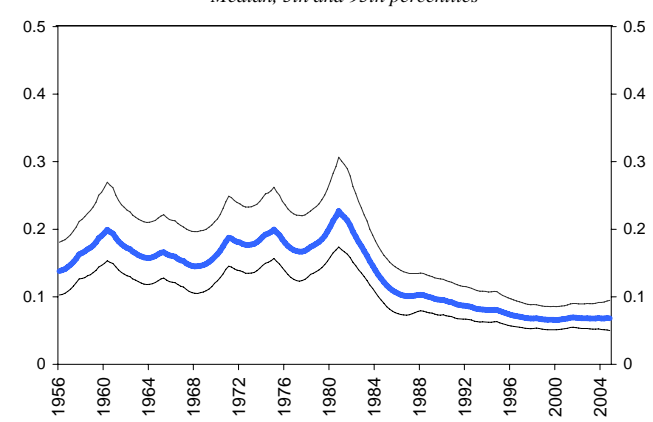

F. Labor Disutility Shock Median, 5th and 95th percentiles

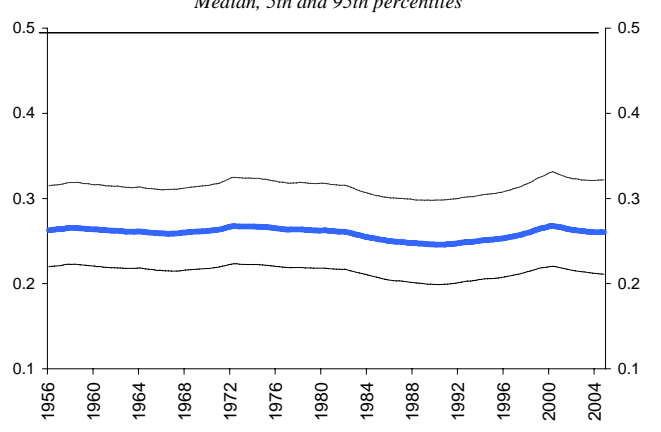


Figure 2: Variance Decomposition for Output Growth 1/
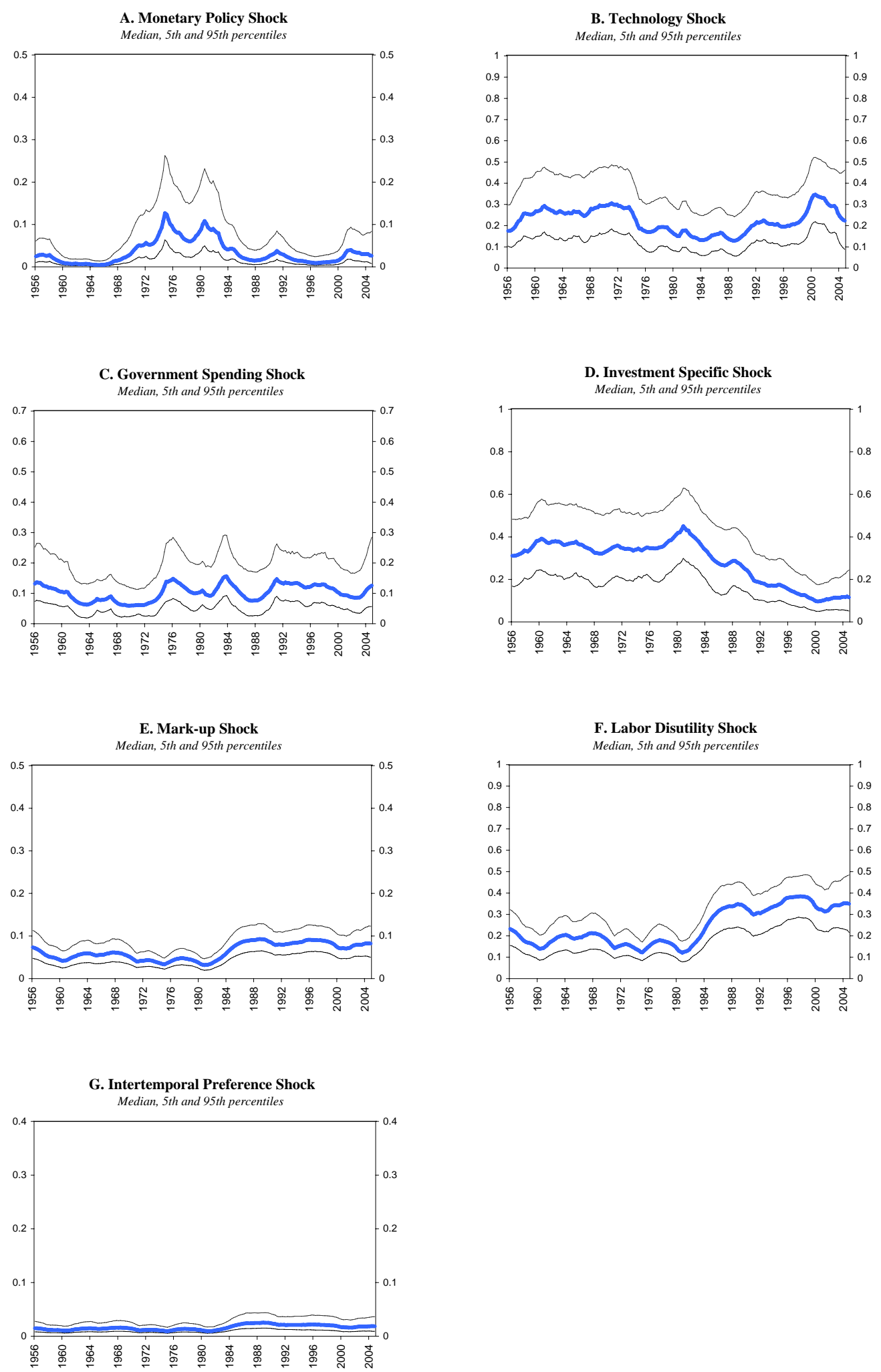

1/ For variance decompositions, medians need not add up to exactly one, but means do 
Figure 3: Selected Variance Decomposition for Other Series

(Series, Shock)

A. Consumption, Intertertemporal Preference Shock Median, 5th and 95th percentiles

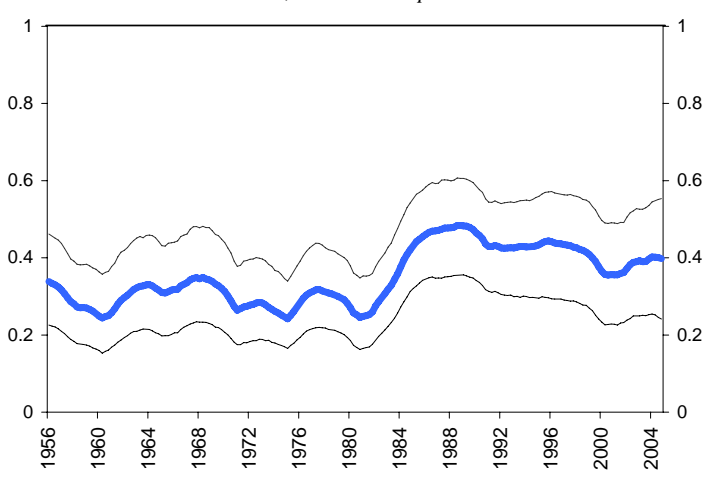

C. Inflation, Mark-up Shock Median, 5th and 95th percentiles

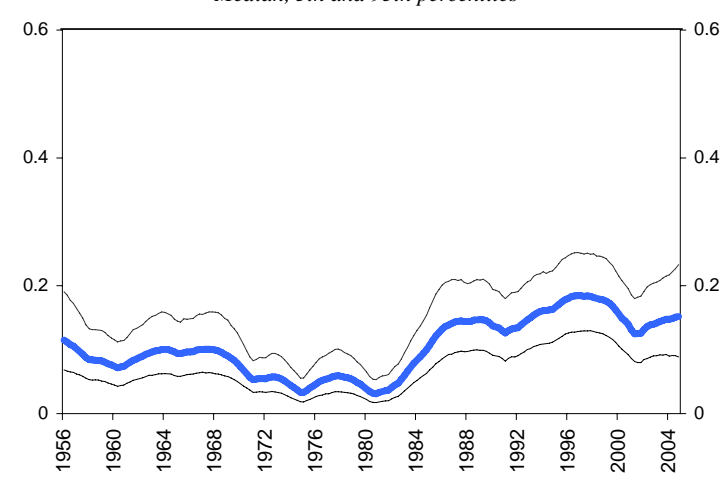

E. Labor, Labor Disutility Shock Median. 5th and 9.5th nercentiles

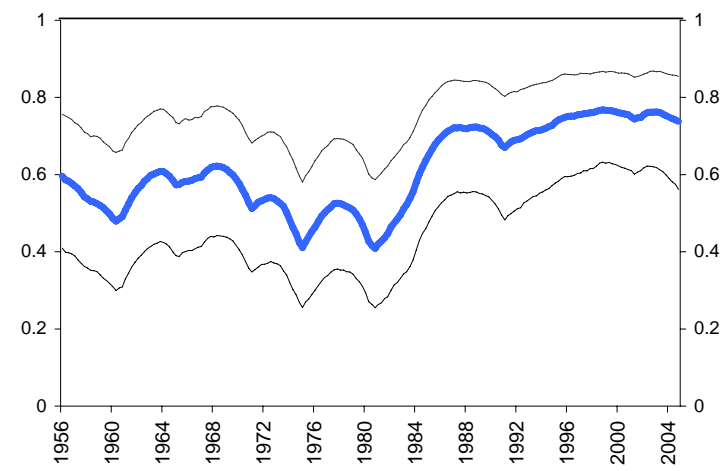

B. FFR, Monetary Policy Shock Median, 5th and 95th percentiles

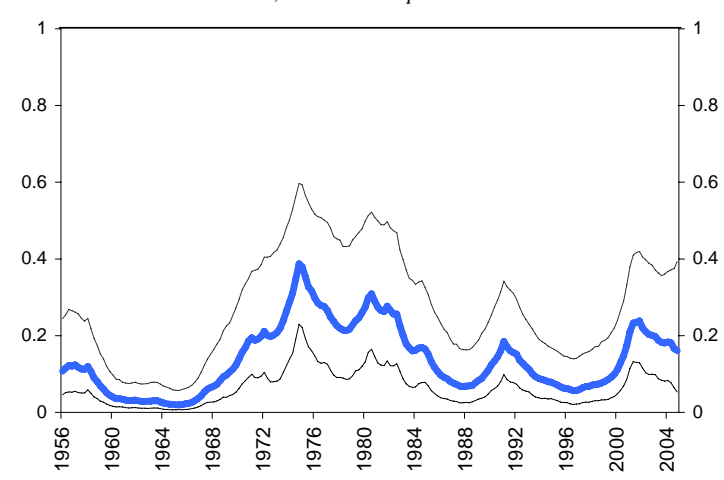

D. Investment, Investment Specific Technology Shock Median, 5th and 95th percentiles

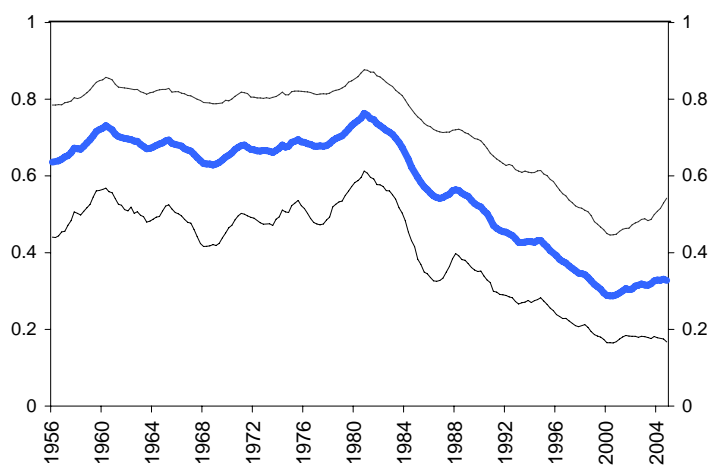

F. Real Wages, Technology Shock Median. 5th and 95th nercentiles

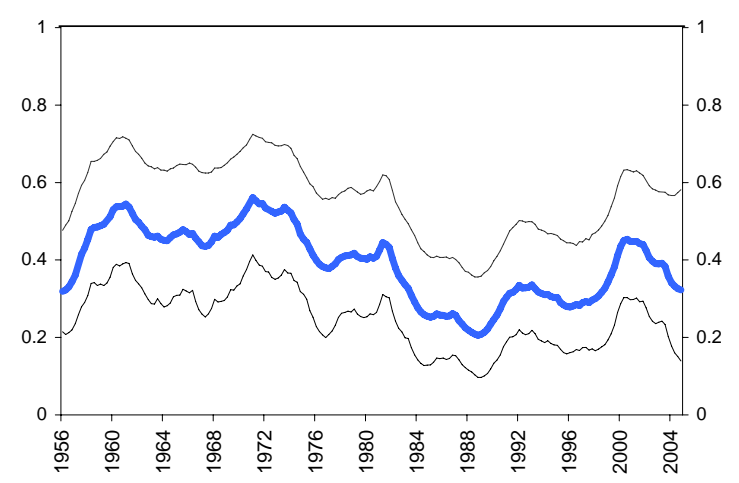


Figure 4: DSGE Spectral Variance Decomposition for Output 1/

Spectrum decomposition for (log) output, in deviations from the model's common stochastic trend, for periodicities between 8 and 32 quarters
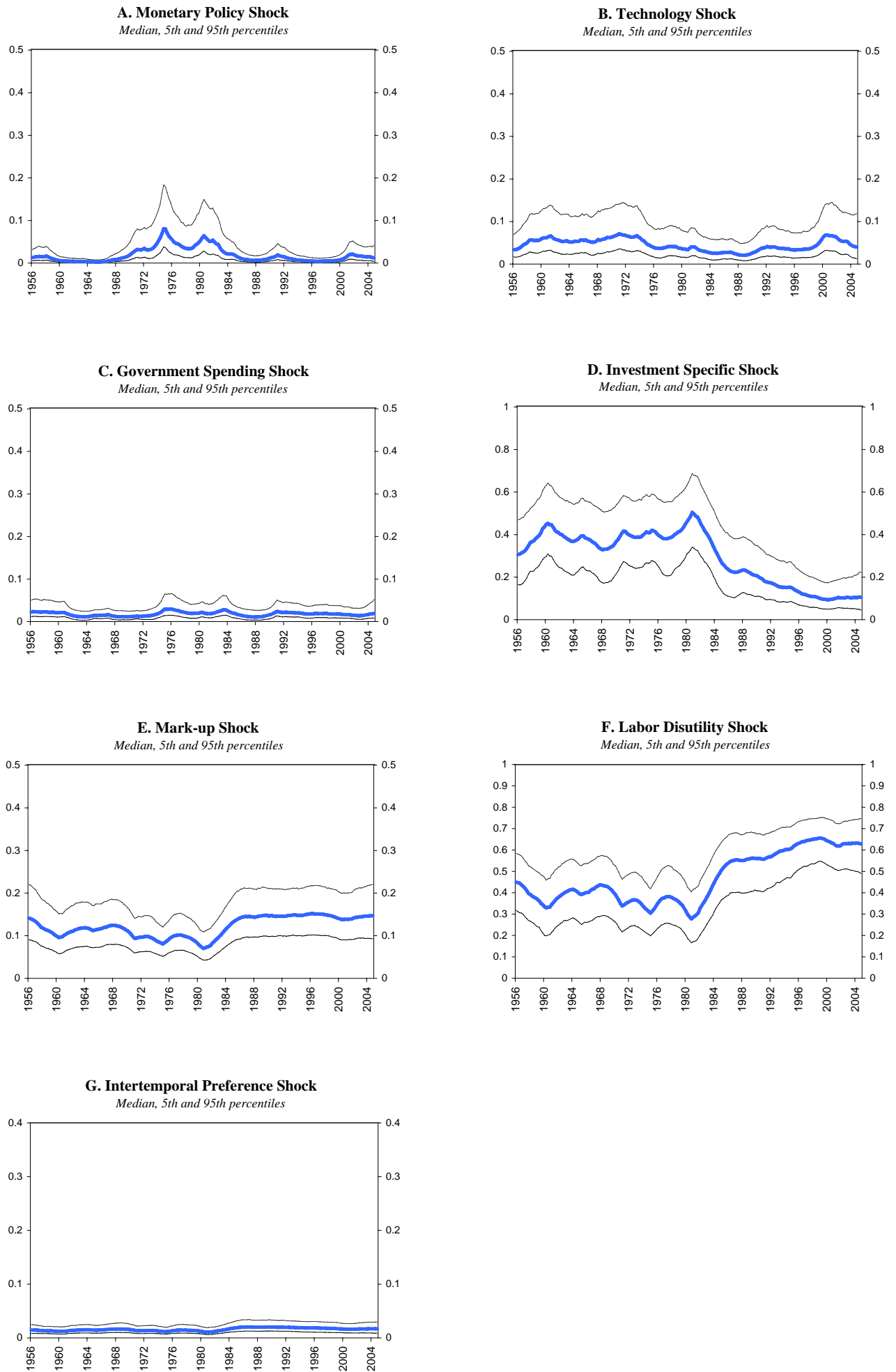

1/ For variance decompositions, medians need not add up to exactly one, but means do 
Figure 5: DSGE Time Varying Standard Deviation of Output Growth and Federal Funds Rate Median, 5th and 95th percentiles

Output Growth

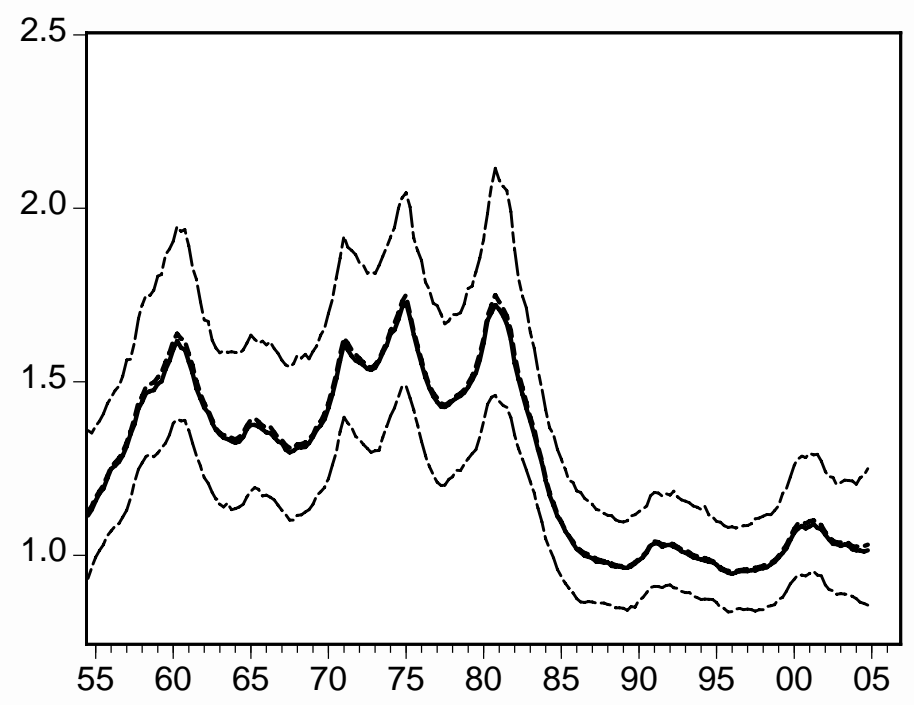

Federal Funds Rate

( Level annualized, multiplied by 4 )

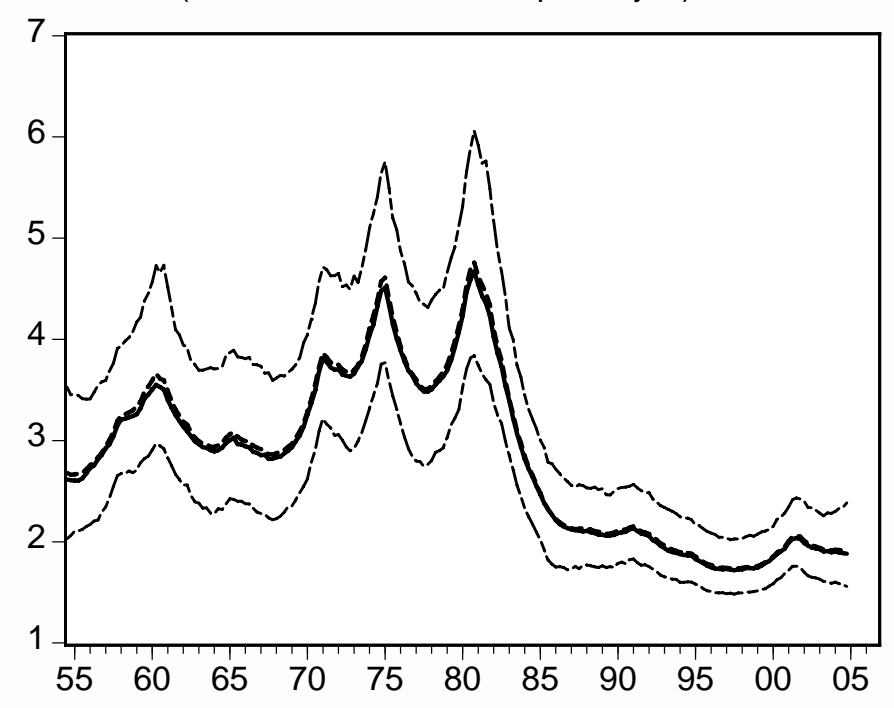


Figure 6: Actual and counterfactual standard deviation (std) for output growth

Counterfactual std obtained by fixing for the remainder of the sample the std of each shock, one at a time, to the average level of the time variying standard deviations in 1980

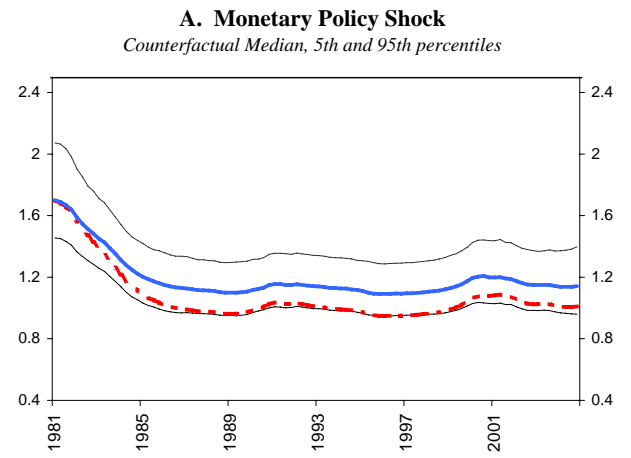

C. Government Spending Shock Counterfactual Median, 5th and 95th percentiles

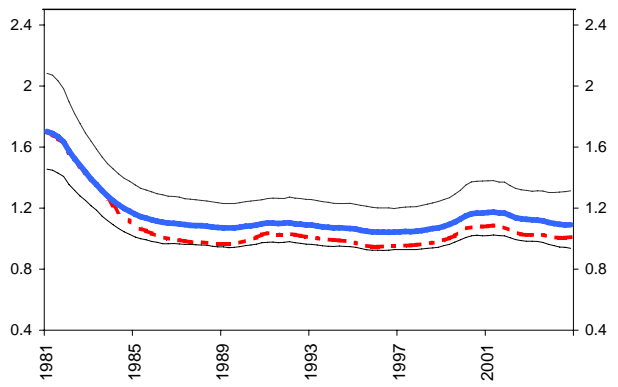

E. Mark-up Shock

Counterfactual Median, 5th and 95th percentiles

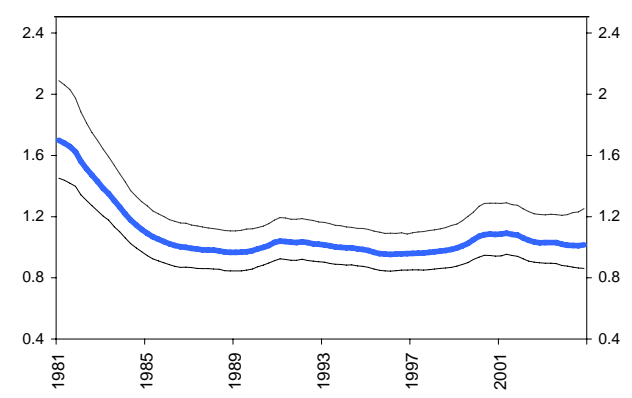

G. Intertemporal Preference Shock Counterfactual Median, 5th and 95th percentiles

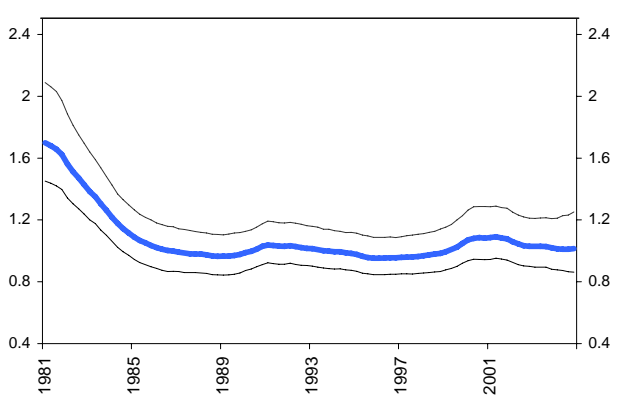

B. Technology Shock Counterfactual Median, 5th and 95th percentiles

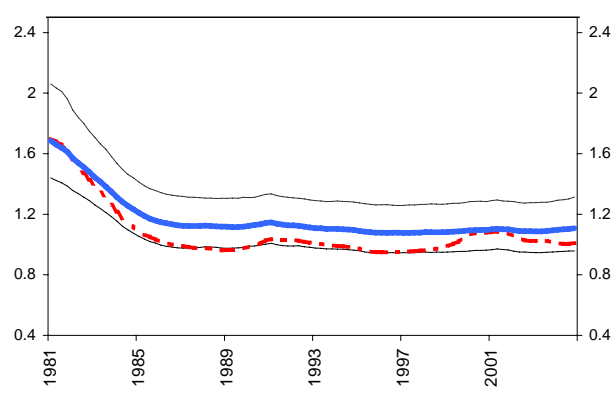

D. Investment Specific Technology Shock Counterfactual Median, 5th and 95th percentiles

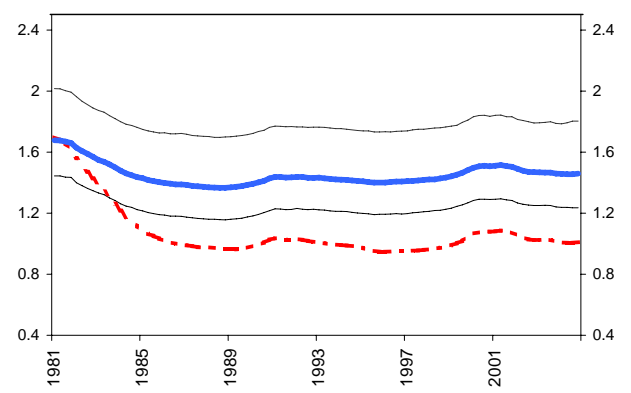

F. Labor Disutility Shock Counterfactual Median, 5th and 95th percentiles
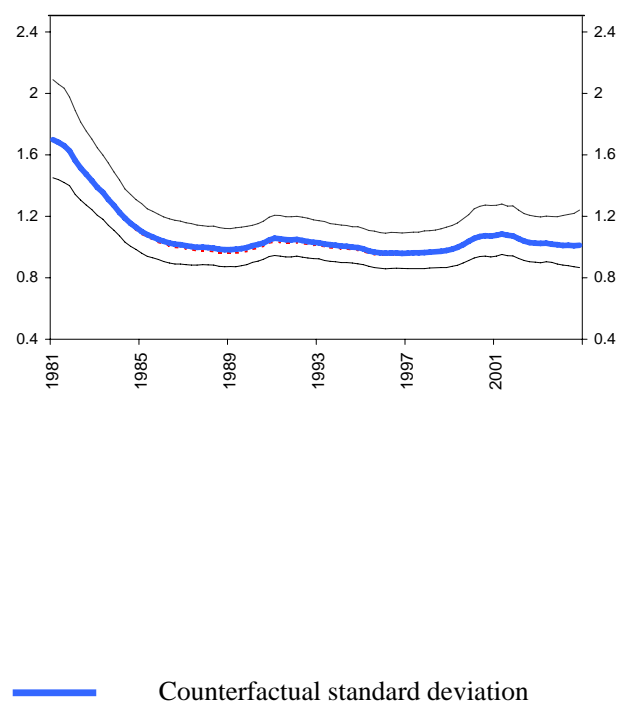

- - Actual standard deviation

5th and 95th percentiles 
Figure 7: Time-Varying Standard Deviation Relative Price of Investment to Consumption

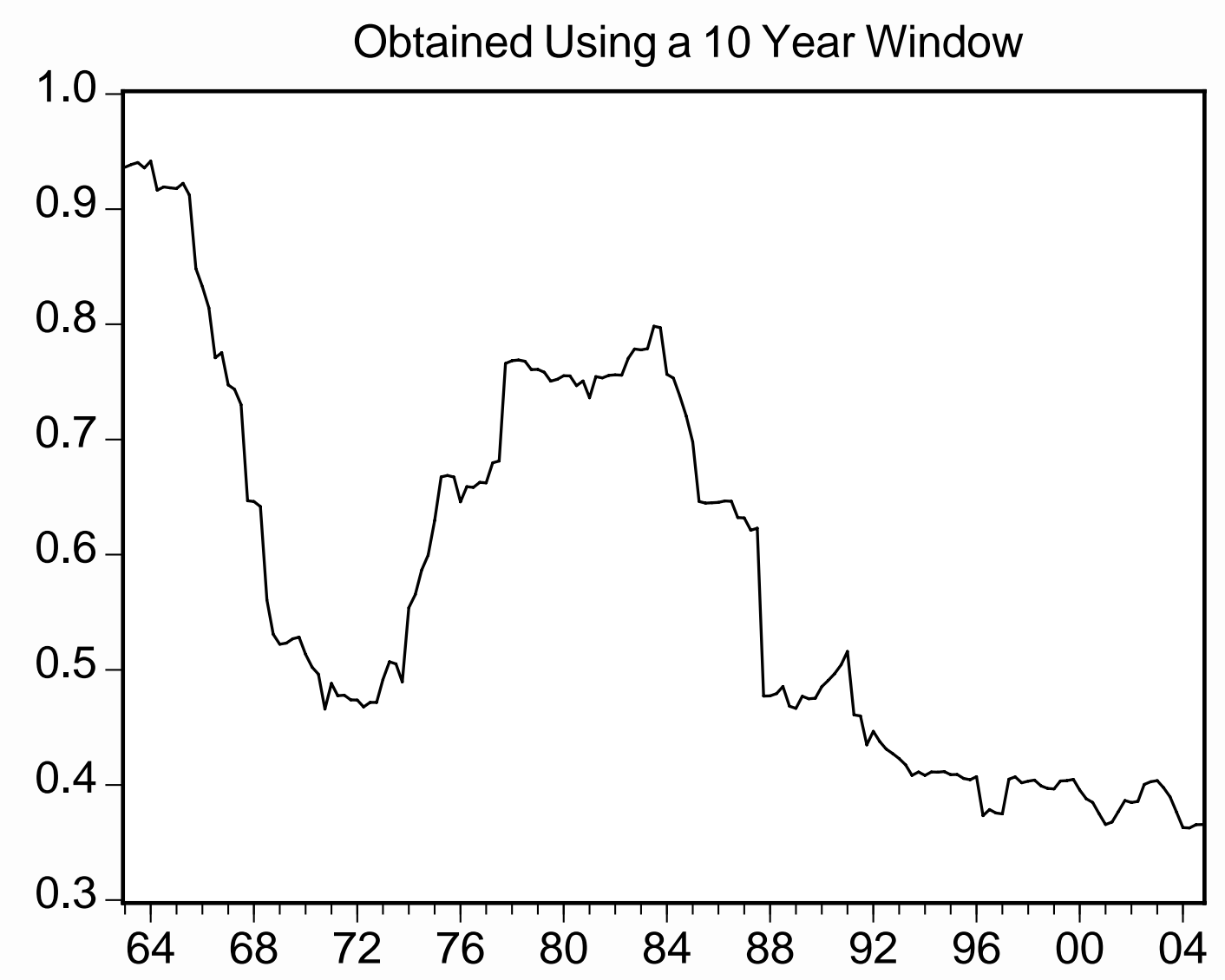


Figure 8: Time Varying Standard Deviations

Median Standard Deviations from an AR(4) with stochastic volatility

A. Consumption

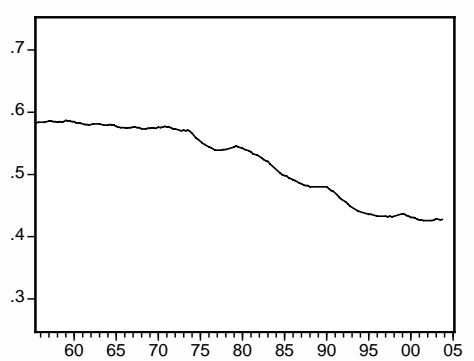

C. Non-Durables

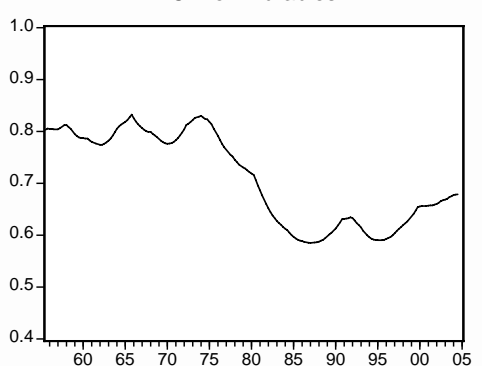

E. Services

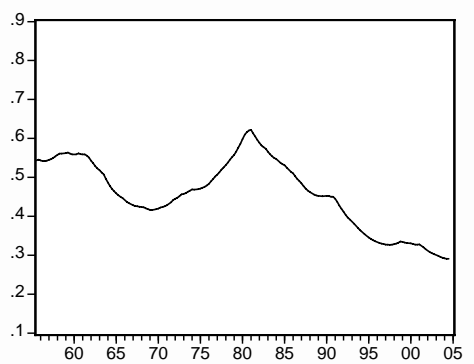

G. Durables

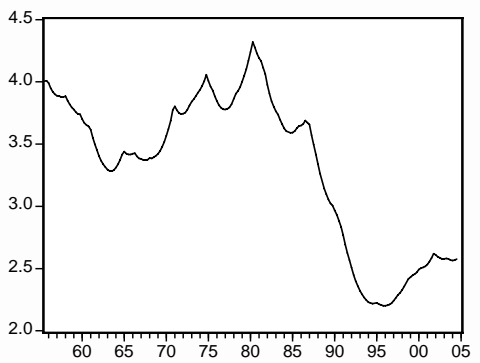

B. Investment

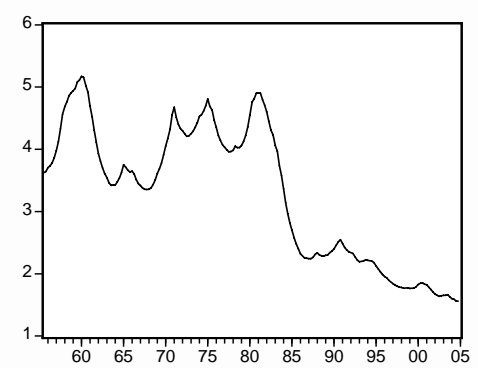

D. Residential

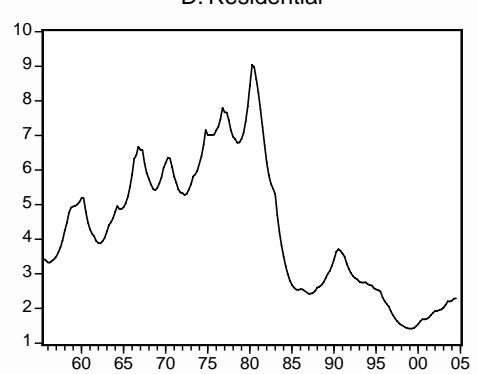

F. Equipment and Software NIPA Deflator

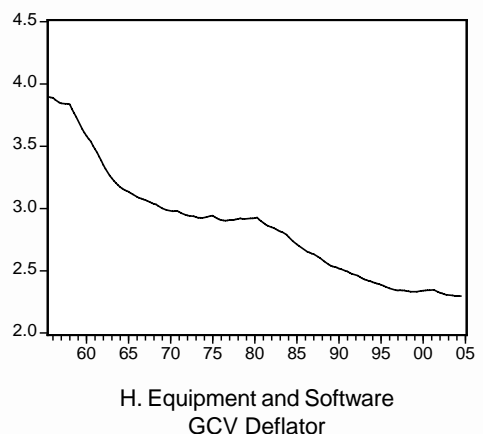

GCV Deflator

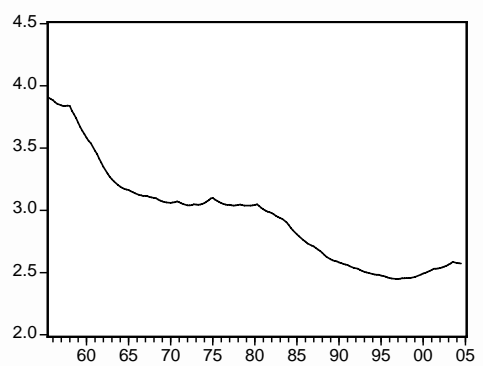

Note: Consistent with the data used to estimate the DSGE model, Consumption corresponds to Non-Durables and Services, while Investment is the sum of Private Investment and Durables 
Figure 9: Mortgage Spreads Levels and Time Varying Standard Deviations

Median standard deviation from an AR(4) with stochastic volatility

Standard Deviation

Spread 30Y Mortgage Rate and Moody's AAA

Spread 30Y Mortgage Rate and Moody's AAA
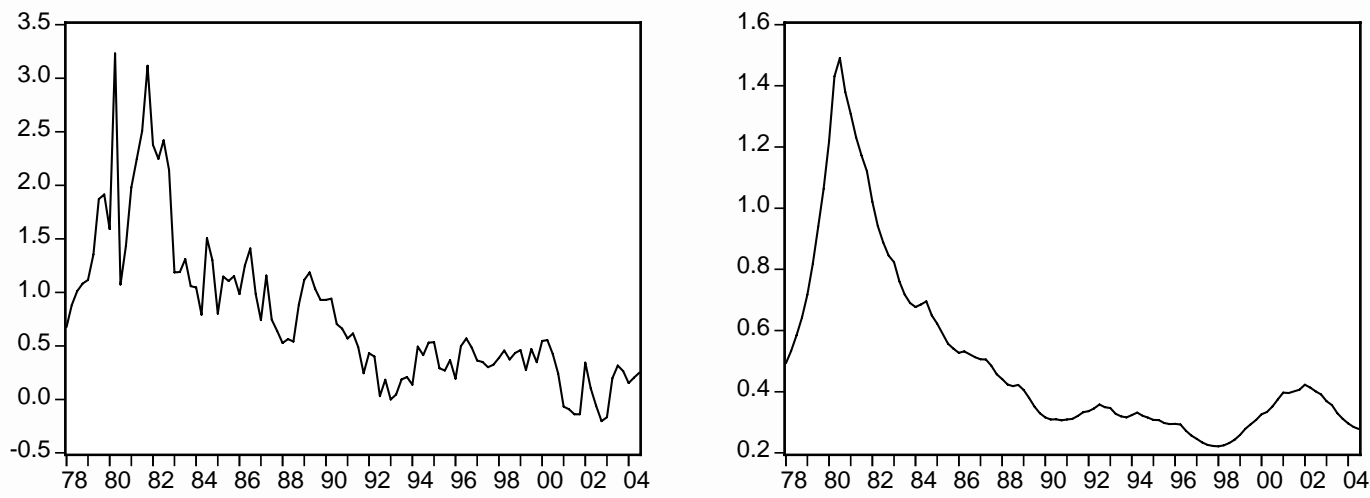

Spread 30Y Mortgage Rate and T-Bill 10Y

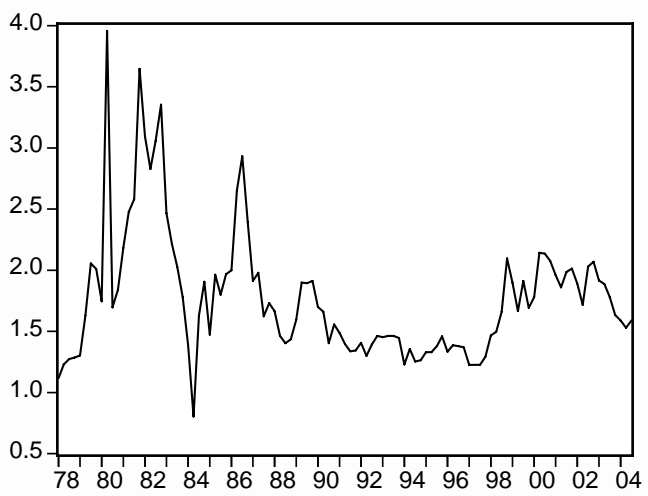

Standard Deviation

Spread 30Y Mortgage Rate and T-Bill 10Y

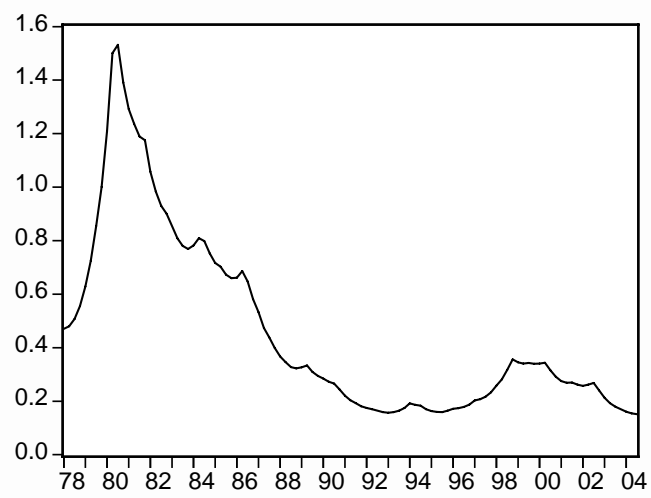

Standard Deviation

Spread 30Y Mortgage Rate and T-Bill 30Y

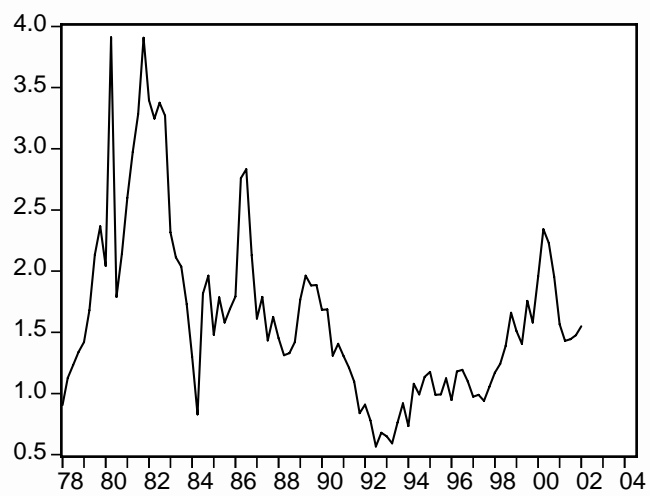

Spread 30Y Mortgage Rate and T-Bill 30Y

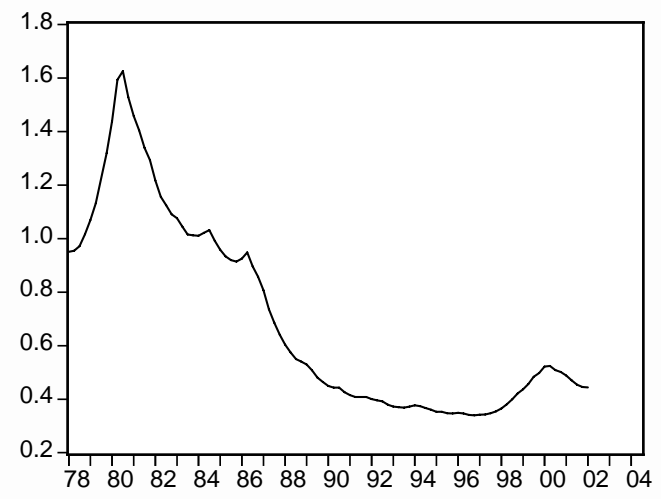


Figure 10: Actual and counterfactual standard deviation (std) for output growth exlcuding stocks

Counterfactual std obtained by fixing for the remainder of the sample the std of each shock, one at a time, to the average level of the time variying standard deviations in 1980

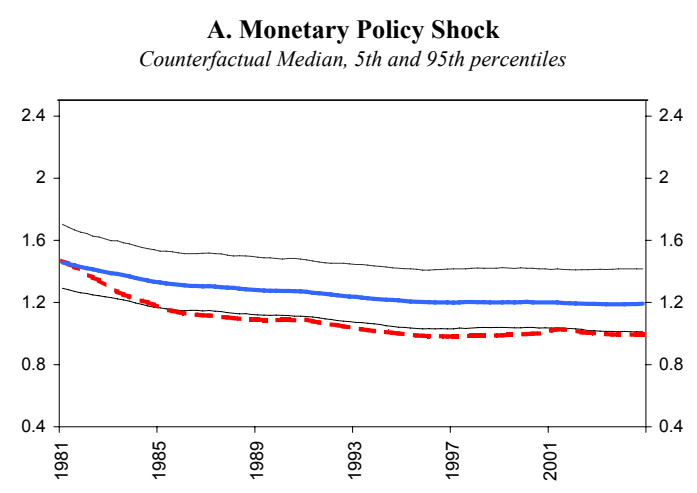

C. Government Spending Shock Counterfactual Median, 5th and 95th percentiles

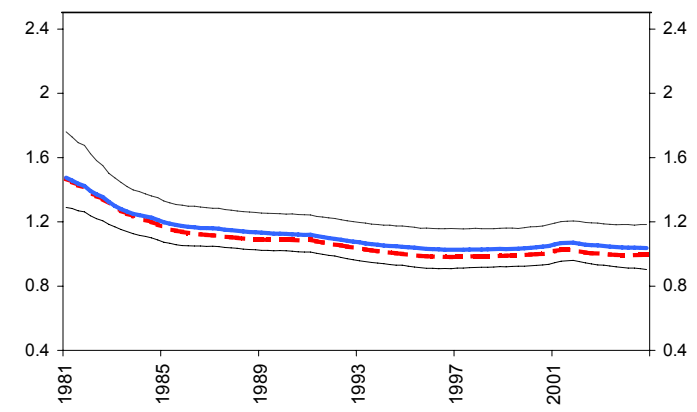

E. Mark-up Shock

Counterfactual Median 5 th and 95 th nercentiles

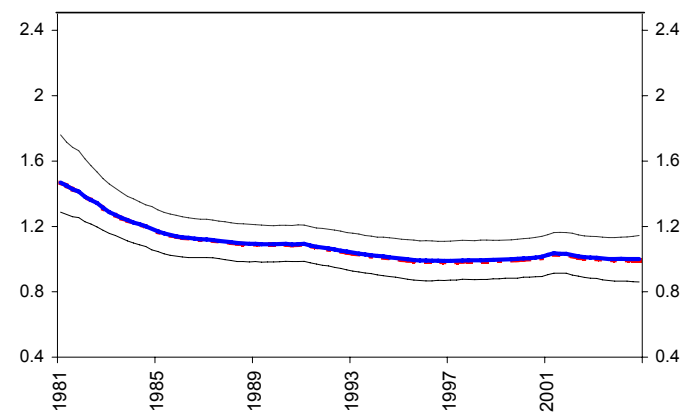

G. Intertemporal Preference Shock Counterfactual Median. 5th and 95th percentiles

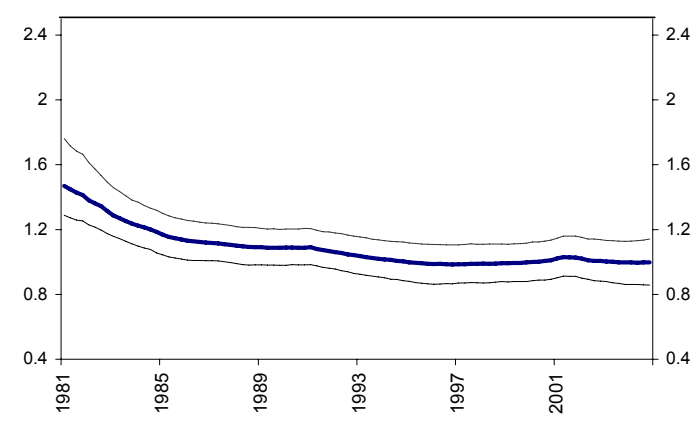

B. Technology Shock

Counterfactual Median, 5th and 95th percentiles

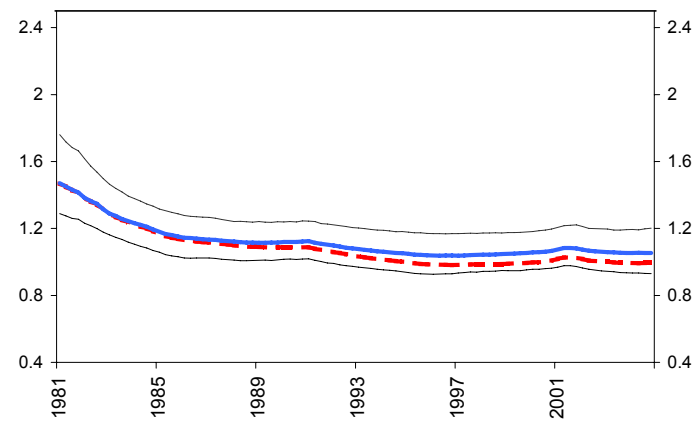

D. Investment Specific Technology Shock Counterfactual Median, 5th and 95th percentiles

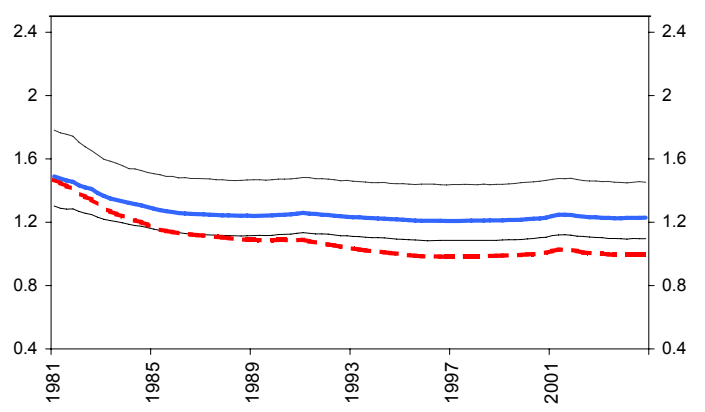

F. Labor Disutility Shock

Counterfactual Median. 5th and 95th percentiles

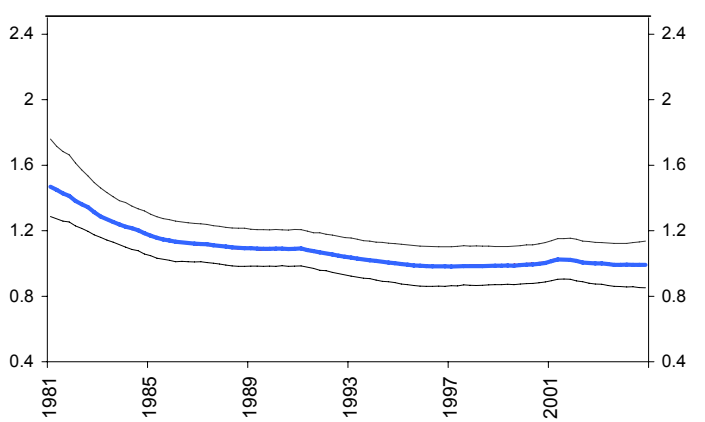

Counterfactual standard deviation

Actual standard deviation

5th and 95th percentiles 